Portland State University

PDXScholar

$12-1997$

\title{
First Language and Gesture Acquisition in Children with Cerebral Palsy
}

Ann Christine Friel

Portland State University

Follow this and additional works at: https://pdxscholar.library.pdx.edu/open_access_etds

Part of the Speech and Hearing Science Commons

Let us know how access to this document benefits you.

\section{Recommended Citation}

Friel, Ann Christine, "First Language and Gesture Acquisition in Children with Cerebral Palsy" (1997). Dissertations and Theses. Paper 5738.

https://doi.org/10.15760/etd.7609

This Thesis is brought to you for free and open access. It has been accepted for inclusion in Dissertations and Theses by an authorized administrator of PDXScholar. Please contact us if we can make this document more accessible: pdxscholar@pdx.edu. 


\section{THESIS APPROVAL}

The abstract and thesis of Ann Christine Friel for the Master of Science in Speech

Communication: Speech and Hearing Science were presented September 3, 1997, and accepted by the thesis committee and the department.

COMMITTEE APPROVALS:

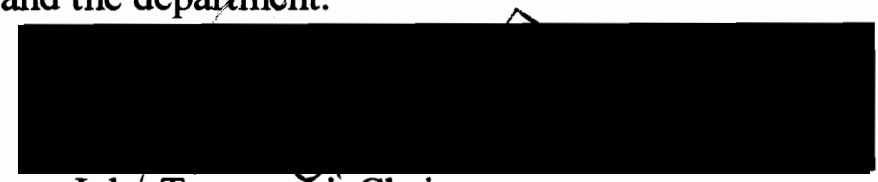

John Tetnowski, Chair

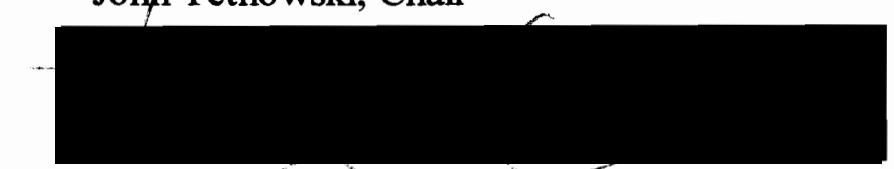

Doug Maptin

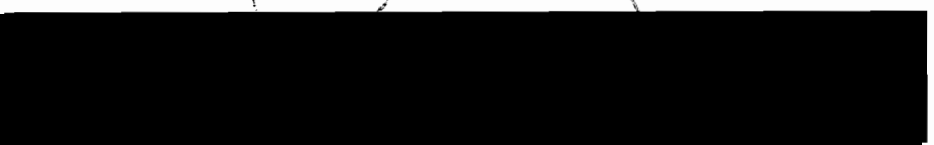

Sheldon Maron

Representative of the Office of Graduate Studies

DEPARTMENT APPROVAL:

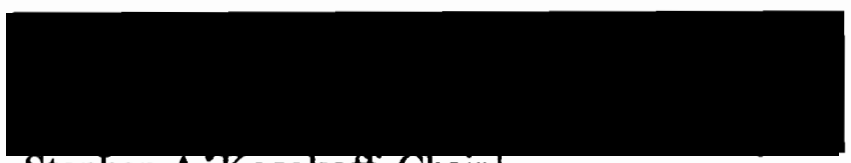

Stephen A. Kosokoft, Chair'

Department of Speech Communication

ACCEPTED FOR PORTLAND STATE UNIVERSITY BY THE LIBRARY

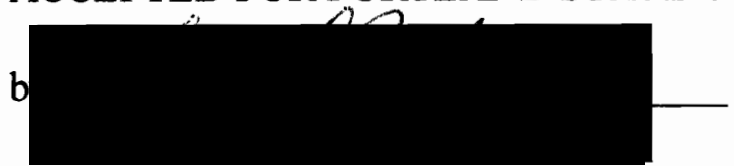

on

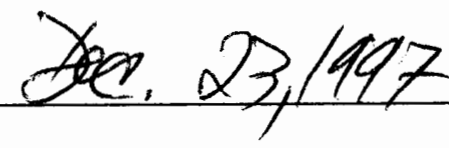




\begin{abstract}
An abstract of the thesis of Ann Christine Friel for the Master of Science in Speech Communication: Speech and Hearing Science presented September 3, 1997.
\end{abstract}

Title: First Language and Gesture Acquisition in Children with Cerebral Palsy.

Many children with Cerebral Palsy (CP) will receive speech and language intervention throughout their lives. However, there is a lack of descriptive data for language and gesture development of children with CP. When assessing the skills of children with $\mathrm{CP}$, standardized tests and clinical observations have several inherent faults due to time constraints, normative data, and physical constraints. An alternative method used to gather data in the area of language and gesture development is parent questionnaire. The MacArthur Communicative Development Inventory: Words \& Gestures was chosen for this study because it has been shown to be an efficient, valid, and reliable tool that can be used with older children who might have delayed skills.

The primary purpose of the present study was to gather descriptive data on the vocabulary and gesture development of 2 to 6-year-old children with $\mathrm{CP}$ who are speaking and nonspeaking. This study also sought to answer the following question: Is there a difference between mean scores of children who are nonspeaking and speaking on measures of phrase and word comprehension and gesture production? 
Seventeen children, 2 to 6 years old, were selected from hospitals, clinics, early intervention programs, and by word of mouth. Subjects were accepted into the study if they had normal or delayed cognitive skills, correctable vision and hearing, $\mathrm{CP}$, and a signed consent form.

The subjects were divided into two groups, speaking and nonspeaking, based on the number of expressive words that parents reported on the MacArthur Communicative Development Inventory: Words \& Gestures. Descriptive data (mean, standard deviation, and range) were tabulated on the MacArthur Communicative Development Inventory: Words \& Gestures for both groups on all six measures (phrase comprehension, comprehended and spoken words, early gesture, later gesture, and total gesture production). The raw scores were then compared to the normative data for typically developing children when age equivalencies were achieved. The mean scores of all measures for both groups were analyzed using the Wilcoxon rank sum equation. The differences between mean scores for all measures between the children who were speaking and nonspeaking was statistically significant at the .05 level. 
FIRST LANGUAGE AND GESTURE ACQUISITION IN

CHILDREN WITH CEREBRAL PALSY

by

ANN CHRISTINE FRIEL

A thesis submitted in partial fulfillment of the

requirements for the degree of

MASTER OF SCIENCE

in

SPEECH COMMUNICATION:

SPEECH AND HEARING SCIENCE

Portland State University

1997 


\section{ACKNOWLEDGMENTS}

Before I thank everyone who knew me during this strenuous and challenging endeavor, I would like to share a thought about life during one's thesis: Your thesis is an important task that can sometimes take over your life; be careful not to lose sight of the things that mean the most to you along the way.

I would like to express a deep and heartfelt thanks to my mother, Becky Westwater, my father, Tom Westwater and my grandmother, Helen Westwater, for the many gifts they have given me, mainly their belief that we can better our lives through education. Through their tireless support and selflessness I have become an educated and productive member of society.

I would like to thank my friends, Laura, Sue, Gail, and Sheryl, for their laughter, time, and encouragement during this task.

I would like to thank Mr. Ralph Coate, Mr. Lynn Sweet, Mrs. Debra Horne, and Mr. Martin Settle for being the kind of educators who inspire and motivate their students.

I would also like to thank Dr. Paul and Dr. Tetnowski for working with me on this project. Their knowledge and expertise were invaluable and much appreciated. 
TABLE OF CONTENTS

PAGE

ACKNOWLEDGMENTS $\ldots \ldots \ldots \ldots \ldots \ldots \ldots \ldots \ldots$ ii

LIST OF TABLES $\ldots \ldots \ldots \ldots \ldots \ldots \ldots \ldots \ldots \ldots \ldots \ldots \ldots \ldots$

LIST OF FIGURES $\ldots \ldots \ldots \ldots \ldots \ldots \ldots \ldots \ldots \ldots \ldots$ vii

CHAPTER

I INTRODUCTION AND STATEMENT OF PURPOSE $\ldots \ldots \ldots \ldots \ldots 1$

Introduction $\ldots \ldots \ldots \ldots \ldots \ldots \ldots \ldots \ldots \ldots \ldots \ldots$

Statement of Purpose $\ldots \ldots \ldots \ldots \ldots \ldots \ldots \ldots \ldots \ldots$

The Research Hypotheses . . . . . . . . . . . . . . . 5

Definition of Terms $\ldots \ldots \ldots \ldots \ldots \ldots \ldots \ldots \ldots$

II REVIEW OF THE LITERATURE $\ldots \ldots \ldots \ldots \ldots \ldots \ldots \ldots \ldots \ldots$

Review of Normal Language and Cognitive Development . . . . . . 12

Development and Cognition in Typical Development . . . . . . 12

Development of Gestures . . . . . . . . . . . . . . 13

Development of Intentional Communication . . . . . . . . . 16

Development of Phonological Skills from Birth to Five . . . . . 18

Lexical Growth and Category Development . . . . . . . . 20

Communication and Cognition in Children with Cerebral Palsy $\ldots \ldots 21$

Types of Cerebral Palsy and Their Effects on Communication $\ldots \ldots 24$

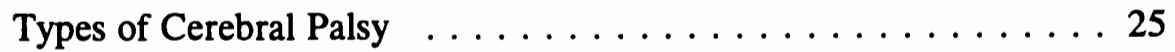

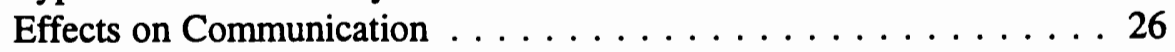

Assessment of Individuals with Cerebral Palsy Who are Nonspeaking $\ldots 28$ 
Assessment of Nonverbal Intelligence . . . . . . . . . . . 28

Assessment of Language . . . . . . . . . . . . . . . 29

Parent Report Instructions: Construction, Reliability, and Validity . . . 30

Summary $\ldots \ldots \ldots \ldots \ldots \ldots \ldots \ldots \ldots \ldots \ldots \ldots \ldots \ldots \ldots \ldots$

III METHODS AND PROCEDURES $\ldots \ldots \ldots \ldots \ldots \ldots \ldots \ldots \ldots \ldots$

Methods ......................... 36

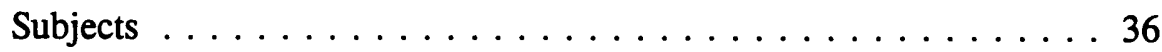

Instrumentation $\ldots \ldots \ldots \ldots \ldots \ldots \ldots \ldots \ldots \ldots \ldots \ldots$

Procedures $\ldots \ldots \ldots \ldots \ldots \ldots \ldots \ldots \ldots \ldots \ldots \ldots \ldots$

Data Analysis .................... 41

Descriptive Statistics ..................42

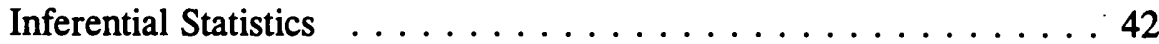

IV RESULTS AND DISCUSSION $\ldots \ldots \ldots \ldots \ldots \ldots \ldots \ldots \ldots$

Results $\ldots \ldots \ldots \ldots \ldots \ldots \ldots \ldots \ldots \ldots \ldots \ldots \ldots$

Children with Cerebral Palsy Who Are Speaking . . . . . . . . 43

Children with Cerebral Palsy Who Are Nonspeaking . . . . . . 45

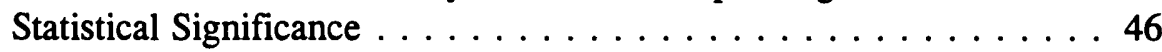

Trends for Both Groups . . . . . . . . . . . . . . 46

Discussion $\ldots \ldots \ldots \ldots \ldots \ldots \ldots \ldots \ldots \ldots \ldots \ldots \ldots \ldots \ldots \ldots \ldots$

$\mathrm{V} \quad$ SUMMARY AND IMPLICATIONS $\ldots \ldots \ldots \ldots \ldots \ldots \ldots \ldots \ldots$

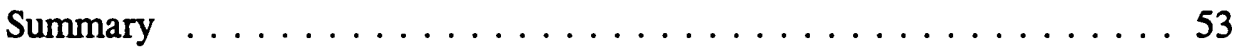

Implications $\ldots \ldots \ldots \ldots \ldots \ldots \ldots \ldots \ldots \ldots \ldots \ldots \ldots \ldots \ldots \ldots$

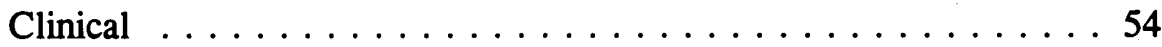

Limitations of the Study . . . . . . . . . . . . . 57

Research ..................... 58

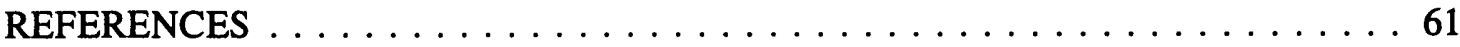




\section{APPENDIXES}

A Informed Consent Form and Cover Letter for Subjects $\ldots \ldots \ldots \ldots$

B Directions for Filling Out the MacArthur Communicative Development Inventory: Words \& Gestures . . . . . . . . . . . . . . 68

C The MacArthur Communicative Development Inventory: Words \&

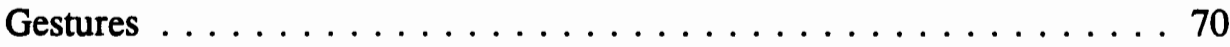

D The MacArthur Communicative Development Inventory: Words \&

Gestures Child Report Form . . . . . . . . . . . . . . . . 79 


\section{LIST OF TABLES}

TABLE

PAGE

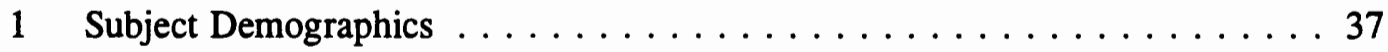

2 Use of an Augmentative and Alternative Communication System . . . . . . 37

3 Cognitive Status as Reported by Parent $\ldots \ldots \ldots \ldots \ldots \ldots$

4 Percentages of Subjects Who Received Speech and Language Intervention . . 38

5 Descriptive Data for Children with CP Who Are Speaking . . . . . . . 44

6 Descriptive Data for Children with CP Who Are Nonspeaking . . . . . . . 45

7 Responding to Language, Starting to Talk, and Symbolic Gestures . . . . . . 47 


\section{LIST OF FIGURES}

FIGURE

PAGE

1 Raw Scores by Age for Number of Receptive Words in Children with CP Who Are Speaking . . . . . . . . . . . . . . . . . 50

2 Raw Scores by Age and Number of Later Gestures in Children with CP Who Are Speaking . . . . . . . . . . . . . . . . 52

3 Raw Scores by Age and Number of Total Gestures in Children with CP Who Are Speaking 


\title{
CHAPTER I
}

\section{INTRODUCTION AND STATEMENT OF PURPOSE}

\author{
Introduction
}

According to Love (1992), cerebral palsy (CP) is a non-progressive disorder of voluntary motion and posture due to brain injury or pathology occurring in the period of early brain growth. CP is characterized by and may consist of paralysis, weakness, uncoordination, or functional aberration of the motor system. Cognition, perception, sensation, language, hearing, emotional behavior, and feeding may be adversely affected. In addition, it may be difficult to control seizures in children with CP. CP is the most common childhood handicapping condition in the United States (Love, 1992).

Children with CP also show a high prevalence of speech and language disorders compared to typically developing children (Hardy, 1983). Some individuals with CP may have dysarthria, muscle weakness, or paralysis in the speech producing musculature. This may reduce oral communication to vocalizations and, thus, the population of children who have severe dysarthria is often referred to as nonspeaking because they cannot talk in words (Adler, 1975). People who are primarily or totally nonspeaking may use an augmentative or alternative communication system (AAC), gestural movements, or eye gaze to communicate (Lloyd \& Karlan, 1983).

Despite the fact that there has been growing research into AAC systems, there appears to be a lack of descriptive research examining the development of language and 
gesture skills of children who have CP ( Lloyd \& Karlan, 1983). Usually, the language and gesture development of children with physical disabilities is compared to descriptive data which have been gathered on typically developing children. The dearth of information on the language skills of this population is unfortunate, considering the fact that a portion of children with CP will require an AAC system in order to communicate (Hardy, 1983). Understanding the language skills these children bring to their AAC systems would help provide the best match of their ability to the assistive equipment.

The cognitive skills of children with CP may or may not be delayed. They may also have varied strengths and weaknesses in developing language skills, with some areas being grossly delayed and others at age level or advanced (Hardy, 1983; Mysak, 1980). For example, a child with normal intelligence who is nonspeaking may have excellent receptive language skills but poor spelling and reading skills due to a lack of exposure in these areas, as well as other detrimental factors caused by the CP (Beringer \& Gans, 1986). Each child with CP may have a different profile when looking at cognitive, language, and motor skills, depending on the type and location of brain damage (Hardy, 1983). For this reason, creating an individualized diagnostic profile benefits both children and professionals when looking for strengths and weaknesses in these areas (Johnson-Martin, Wolters, \& Stowers, 1987). However, assessing the cognitive and language skills of children with $C P$ who are also nonspeaking can be a cumbersome task because the response modes of many tests require fine motor control (e.g., talking or pointing) (Johnson-Martin et al., 1987).

While assessing the language skills of people with CP who are nonspeaking and of normal intelligence, Beringer and Gans (1986) found that receptive language at the conversational level was their strongest skill. This is an important finding, since other 
language skills were quite delayed when compared to the age appropriate scores for receptive language. With this in mind, it would be interesting to see if differences in receptive word knowledge exist between children with $\mathrm{CP}$ who are speaking and children with CP who are nonspeaking. Thal and Bates (1988), and Thal and Tobias (1994) found that the ability to sequence gestures and gesture rates are highly correlated with good receptive language skills in typically developing children with and without normal expressive language skills. Children who did not have good receptive vocabulary skills had poorer gesture production skills when compared to children with expressive and receptive language skills within the normal range and when compared to children with only expressive language delays. It is widely accepted that most children have higher receptive vocabularies than expressive vocabularies. In normal language development, a child's receptive and expressive vocabulary grows over time (Owens, 1988). Also, it is widely accepted that receptive and expressive vocabulary grow in conjunction with one another in normal language development. If we were to apply this information to children with $\mathrm{CP}$ who are nonspeaking, it might speculated that children with $\mathrm{CP}$ who are speaking might have higher receptive word knowledge and higher gesture production rates than their nonspeaking counterparts because they have higher expressive vocabulary. With these factors in mind, it would appear valuable to investigate measures of receptive vocabulary and gesture production for the two groups of children with CP (speaking and nonspeaking).

As a result of the difficulties that arise when trying to assess the cognitive and language skills for a child with CP, one must look to other methods for gathering supplemental information. Although there are some limitations, many researchers today rely on the input of parents, via parent questionnaire, to efficiently attain reliable information for 
a variety of measures (Fenson et al., 1993; Rescorla, 1991). Currently, there are no parent questionnaires that focus specifically on the language and gestures of children with disabilities (Fenson et al., 1993). Therefore, in order to gather information on language and gestures for children who generally show large delays in these areas, it would appear logical to select a parent questionnaire that targets the language and gestures of a younger but typically developing population (Fenson et al., 1993). Such a tool is the MacArthur Communicative Development Inventory: Words \& Gestures (Fenson et al., 1993).

Gathering descriptive data on the language and gesture skills of children with $\mathrm{CP}$ who are speaking and nonspeaking via parent report would serve two purposes. First, it would provide an initial body of descriptive data for expressive and receptive words and gesture production. Secondly, the children with $\mathrm{CP}$ would be divided into speaking and nonspeaking groups based on their number of expressive words reported on the parent questionnaire. The performance of these two groups could be compared for measures of word and phrase comprehension, and gesture production. If differences exist, inferences could be made as to which factors may be influencing the development of the two groups of subjects.

\section{Statement of Purpose}

The purpose of this research is to obtain descriptive data (mean, standard deviation, range) on the expressive and receptive language and gesture production of children with $\mathrm{CP}$ who are speaking and nonspeaking and are between the ages of 2 and 6 years old, via a parent report instrument (i.e., MacArthur Communicative Development Inventory: Words \& Gestures) (Fenson et al., 1993). These results will then be compared to normative data on 
the MacArthur Communicative Development Inventory: Words \& Gestures. In addition, the subjects will be divided into two groups based on the number of expressive words reported. Those children who produce fewer than 20 words will be considered nonspeaking and those who produce 20 words or more will be considered speaking. The data from these groups will be analyzed to see if there are significant differences between the groups for measures of receptive language (phrases and words) and expressive gesture production (early, later, and total gestures).

\section{The Research Hypotheses}

The following research hypotheses have been developed:

1. Children who are nonspeaking and have $\mathrm{CP}$ will be reported by parents to have a significantly different mean score for phrases comprehended than children who are speaking and have $\mathrm{CP}$, as assessed using the MacArthur Communicative Development Inventory: Words \& Gestures.

2. Children who are nonspeaking and have $\mathrm{CP}$ will be reported by parents to have a significantly different mean score for understood words than children who are speaking and have $\mathrm{CP}$, as assessed using the MacArthur Communicative Development Inventory: Words \& Gestures.

3. Children who are nonspeaking and have CP will be reported by parents to have a significantly different mean score for early gestures than children who are speaking and have $\mathrm{CP}$, as assessed using the MacArthur Communicative Development Inventory: Words \& Gestures. 
4. Children who are nonspeaking and have $\mathrm{CP}$ will be reported by parents to have a significantly different mean score for later gestures than children who are speaking and have $\mathrm{CP}$, as assessed using the MacArthur Communicative Development Inventory: Words \& Gestures.

5. Children who are nonspeaking and have $\mathrm{CP}$ will be reported by parents to have a significantly different mean score for total gestures than children who are speaking and have $\mathrm{CP}$, as assessed by parent report using the MacArthur Communicative Development Inventory: Words \& Gestures.

\section{Definition of Terms}

ataxic: A type of CP characterized by dyscoordination and tremors in both fine and gross motor activity; speech is characterized by inconsistent articulatory errors and difficulty with the normal speed of conversation (Nicolosi, Harryman, \& Kresheck, 1996).

athetoid: a type of CP characterized by involuntary, primarily writhing, movements usually occurring with and blocking volitional efforts (Nicolosi et al., 1996).

augmentative and alternative communication: The use of nonvocal instruments and approaches by those who cannot communicate vocally, which may include picture boards and computer-assisted devices (Nicolosi et al., 1996).

categorization: When children are able to group like objects or experiences and use words to indicate categories, e.g. the word fruit indicates a type of food, examples of which are bananas, oranges, peaches, pears, etc.

cerebellum: The portion of the brain located at the posterior base of the cranial cavity beneath the occipital and temporal lobes of the cerebrum, from which it is separated 
by a membrane (tentorium). It is attached to the medulla, pons, and midbrain of the brainstem by three pairs of tracts which connect it with the cerebrum, brainstem, and spinal cord, enabling it to coordinate body motor function initiated by the cerebrum and to maintain muscle tone and equilibrium (Nicolosi et al., 1996).

cerebral palsy (CP): Defined by Love (1992) as a non-progressive disorder of voluntary motion and posture due to brain injury or pathology occurring in the period of early brain growth.

conservation: In cognitive development, the conceptualization that the amount of quantity of matter stays the same regardless of any changes in shape or position (Nicolosi, et al., 1996)

deictic terms: These terms denote deixis or the linguistic device that anchors the utterance to the communicative setting in which it occurs (e.g., person, a linguistic device to indicate who the speaker is and who the listener is, or place, a linguistic device to indicate where the speaker and listener are at the time of the utterance (Nicolosi et al., 1996).

diplegia: Bilateral paralysis affecting like parts on both sides of the body (Nicolosi et al., 1996).

dysarthria: Term for a collection of motor speech disorders due to impairment originating in the central or peripheral nervous system. Respiration, articulation, phonation, resonation, and/or prosody may be affected; volitional and automatic actions, such as chewing and swallowing, and movements of the jaw and tongue may also be deviant (Nicolosi et al., 1996).

dystonia: Involuntary, rhythmic, twisting distortions of the trunk (Nicolosi et al., 1996). 
dystrophy: Weakness of a tissue, especially of muscle, as may occur in a neuromuscular disorder; may result in atrophy (Nicolosi et al., 1996).

expressive language: One's ability to communicate via the spoken or written word (Nicolosi et al., 1996).

extra-pyramidal system: A functional rather than anatomical unit comprising nuclei and nerve fibers chiefly involved in subconscious, automatic aspects of motor coordination, but which also help regulate postural and locomotor movements (Nicolosi et al., 1996).

extensor muscle: A muscle, the contraction of which tends to straighten a limb; the antagonist of a flexor muscle (Nicolosi et al., 1996).

flexor muscle: A muscle, the action of which is to move a joint; the agonist of an extensor muscle (Nicolosi et al., 1996).

hemiplegia: Paralysis of one side of the body (Nicolosi et al., 1996).

hypernasality: a disorder of resonance which is characterized by an excessively undesirable amount of perceived nasal cavity resonance during phonation (Nicolosi et al., 1996).

hypertrophy: Enlargement of a part or an organ due to an increase in the bulk (but not number) of its elements, not due to tumor formation (Nicolosi et al., 1996).

hyponasality: Lack of nasal resonance for the three phonemes $/ \mathrm{m} /, / \mathrm{n} /$, and $n g / \mathrm{n} /$, resulting from a partial or complete obstruction in the nasal tract (Nicolosi et al., 1996).

illocutionary: Preverbal stage. This is the second stage in the development of intentional behavior (around 9 months), when a child uses behaviors to intentionally gain an adult's attention (e.g., reaching or waving). The child will check to see if an adult is 
attending to his/her communicative attempt and may use a word or joint reference paired with a gesture (pointing) to get what he/she wants (Haynes \& Schulman, 1994).

joint reference: When a parent and child establish a common focus on an entity or event by using eye gaze (Haynes \& Shulman, 1994).

lexicon: The amount of vocabulary words in a given language (Nicolosi et al., 1996).

locutionary: Verbal stage. The third stage in the development of intentionality (13 to $18+$ months) is marked by goal-directed behavior and the ability to share one's goals with others using one to two words. The child realizes that they are an agent who can make things happen with words and other communicative efforts (Haynes \& Schulman, 1994). mean length of utterance (MLU): This is a systematic way of calculating the average length of oral expressions as measured by a representative sampling of oral language, usually obtained by counting the number of morphemes per utterance and dividing by the number of utterances (Nicolosi et al., 1996).

morpheme: The smallest meaningful unit of language having a differential function (Nicolosi et al., 1996).

motor cortex/area: Posterior part of frontal lobe anterior to the central sulcus from which impulses for volitional movement arise (Clayton, 1989).

multiword stage: This term means the stage when a child can use more than one word to communicate verbally (Haynes \& Schulman, 1994).

nominals: In grammar, a word, phrase, or clause that is equivalent to a noun in its structural role (Nicolosi et al., 1996). 
paraplegia: Paralysis of both legs, generally, the lower trunk, but without involvement of the arms (Nicolosi et al., 1996).

prelocutionary: The first stage of intentional communication, from birth to 9 months, in which most of a child's behavior is described as functional communication without goal directedness in mind. The infant does not intentionally cry or smile to seek a response from an adult, but rather the adult interprets these actions as being intentional (Haynes \& Schulman, 1994).

preoperational period: The second stage of Piaget's cognitive development framework ( 2 to 7 years), is characterized by the development of language and rapid conceptual development; intellectual behavior moves to a conceptual level, and by the end of this period the child's thought is prelogical (Nicolosi et al., 1996).

quadriplegia: This term means paralysis involving all four extremities (Nicolosi et al., 1996).

quantitative: Research that generates data capable of being organized in graphs and descriptive statistical forms (Pannbacker \& Middleton, 1994).

recognitory gestures: These gestures are communicative in intent and generally appear in the illocutionary period. Examples of these gestures include pointing, showing objects to others, and giving objects to others (Haynes \& Schulman, 1994).

rigidity: Muscular resistance to passive motion from simultaneous agonist and antagonist muscle group contractions (Nicolosi et al., 1996).

sensorimotor period: The first stage of Piaget's framework for cognitive development ( 0 to 2 years); behavior is primarily motor; there is no conceptual thinking, 
although the infant's reflexive behavior gradually grows into intellectual behavior (Nicolosi et al., 1996).

spastic(ity): Hypertonicity of muscle, characterized by hyperactivity of the stretch reflex; speech is characterized by a slow, labored rate, lack of vocal inflection, guttural or breathy quality of voice, uncontrolled volume, and severe articulatory problems (Nicolosi et al., 1996).

superordinate words: These words represent a larger group or category of any type of noun. For example, the word meat is a superordinate word, because it refers to any type of food that comes from an animal (e.g., beef, poultry, pork, venison, fish).

symbolic play skills: These skills develop at the end of the sensorimotor period and are characterized by the following behaviors: (a) activities are carried out without the usual material, contexts, or outcomes; (b) inanimate objects are treated as animate; (c) an object or gesture may be substituted for the real object or action; or (d) the child carries out an action usually done by someone else ( Fein, 1981).

tremor: Rhythmic, repetitive, involuntary contractions of flexor and extensor muscles, a generalized trembling of the extremities; speech is characterized by vocal arrests resembling spastic dysphonia, monopitch, intermittent strained or strangled harshness, pitch breaks, and tremulous or quavering speech (Nicolosi et al., 1996).

validity: Appropriateness of information gathered to accurately answer a specific question (Pannbacker \& Middleton, 1994). 


\section{CHAPTER II}

\section{REVIEW OF THE LITERATURE}

\section{Review of Normal Language and Cognitive Development}

In this section, research will be reviewed that is based on typically developing children in the following areas: cognition, gestures, intentional communication, phonological skills, lexical growth, and lexical categorization skills. Because many children with cerebral palsy (CP) do not have typically developing skills in these areas as a result of motor or neurological damage, the following information may serve as a benchmark when comparing age and cognitive level expectations. Also, since many communication and cognitive milestones are closely tied together, the information on both of these areas may be used to better understand the cognitive status of the child with CP who is nonspeaking.

\section{Development and Cognition in Typical Development}

Several models of human cognition assert that cognitive development is the "result of a complex intertwining of maturation, social and physical experiences, and equilibrium" (Haynes \& Schulman, 1994, p. 65). Piaget, a leading scientist in the field of cognitive development, constructed four basic stages of cognitive development for children at different age levels. He asserted that children attain the cognitive milestones in these stages at varying ages, but usually pass through the stages in invariant order (Haynes \& Schulman, 1994). In the sensorimotor stage, (birth to 2 years) the child is labeled preverbal or prerepresentational. In the first 8 months of this stage, the child makes the transition from 
reflexive behavior to acting upon objects in his/her environment. At 8 to 12 months, a child begins to coordinate planned series of events with goal directedness in mind. At 12 to 18 months, children develop basic problem-solving skills in a trial and error methodology (Haynes \& Schulman, 1994). Imitation is a key milestone during this stage, and it may be an important vehicle for developing gestures, language, speech, and other communication skills. From 18 to 24 months, children begin to use their mental tools to solve problems before acting and are thus labeled representational (Haynes \& Schulman, 1994). According to Piaget, attainment of the representational milestone is the precursor to learning symbolic systems, such as language or gestures (Haynes \& Schulman, 1994).

In the preschool preoperational stage ( 2 to 4 years), language expression and comprehension grow and become more complex (Haynes \& Schulman, 1994). Emotion, creativity, and representational skills are expressed as pretend play and thus, symbolic play skills begin to develop.

The school age preoperational period takes place between the ages of 4 and 7 years. The ideas of categorization, conservation, and a general awareness of space, time, and quantity develop during this stage (Haynes \& Schulman, 1994).

These cognitive milestones are also accompanied by gesture milestones. Gestures mark the beginning of intentionality and tend to grow and change along with language comprehension and production. Therefore, it is important to review the research on development of symbolic gestures in children.

\section{Development of Gestures}

The development of gestures coincides with cognitive and motoric milestones (Haynes \& Schulman, 1994). In the first year of life, a child's gestures change from 
unintentional random actions to intentional actions. These changes coincide with the child having multiple experiences with many objects and people (Haynes \& Schulman, 1994). In a review of the literature, Zinober and Martlew (1985, as cited in Owens, 1988) found that gestures have been divided into four categories and are acquired by children in the following order: expressive, instrumental, enactive, and deictic (Haynes \& Schulman, 1993).

The expressive gestures, manifested via early motoric milestones (e.g., hand clapping or whole body movements) are demonstrated in early development and convey the emotional state of the child (Zinober \& Martlew, 1985, as cited in Owens, 1988).

Recognitory gestures, also labeled instrumental gestures, such as showing, pointing and giving, appear to be attempts to draw an adult's attention to actions or objects, thus strengthening the joint focus between the two partners (Haynes \& Schulman, 1994). Bates, Benigni, Bretherton, Camaioni, and Volterra (1979) have asserted that these gestures play an important role in laying the foundation for intentional communication. Recognitory gestures serve the purpose of regulating the behavior of the caregiver and are demonstrated as intentionality develops (Zinober \& Martlew, 1985, as cited in Owens, 1988). An example of a recognitory gesture might be a child tapping on a door in front of an adult because they want the adult to open the door.

Enactive gestures and symbolic gestures develop as a child's play and representational skills grow. The enactive gestures demonstrate the child's familiarity with daily routines and objects, so much so that they are able to act them out in a pretend fashion (e.g., pretending to bathe) (Zinober \& Martlew, 1985, as cited in Owens, 1988). Fenson, Kagan, Kearsley, \& Zelazo (1976) believe that it is this understanding of people, actions, and objects in their daily environment that lays the foundation for representational thought. 
As time passes, enactive gestures become more advanced and truly symbolic, because children are able to translate pretend actions to inanimate objects and people during play (e.g., feeding a doll with a block in the place of an apple) (Fenson \& Ramsay, 1981; Zinober \& Martlew, 1985, as cited in Owens, 1988). Piaget (1962) was the first to list these kinds of gestures as being truly symbolic when carried out on other people or objects and not with the child's body alone. In Fein's (1981) description of symbolic play, one can see that play is the usual setting for symbolic gestures. Fein (1981) describes symbolic play as having the following characteristics: (a) activities are carried out without the usual materials, contexts, or outcomes; (b) inanimate objects are treated as animate; (c) an object or gesture may be substituted for the real object or action; or (d) the child carries out an action done by someone else. Lastly, deictic gestures have been described as the "showing of objects to other people or pointing at an object" (Haynes \& Schulman, 1994, p. 235).

Acredolo and Goodwyn (1988) found that children (age 17 months) use a wide range of gesture referents. Gestures were used on a daily basis to represent many different objects, states, and desires, and the most frequently used gestures/referents are similar to the most frequently used words (Acredolo \& Goodwyn, 1988). The children in their study tended to use a gesture until they had a comparable word to express the same meaning. Additionally, object and request gestures were used the most by the subjects (Acredolo \& Goodwyn, 1988). Acredolo and Goodwyn (1988) believe that these early gestures are symbolic of the child's realization that things have names.

In another study of older children (age 11 to 24 months), Acredolo and Goodwyn (1988) found that a wide range of symbolic gestures were used by all children and that females had higher rates of gestures. A positive correlation between object gestures and 
verbal development was noted. Also, gestures were found to play a coordinated role in communication development and tended to grow in conjunction with verbal development in normal children (Acredolo \& Goodwyn, 1988). Haynes and Schulman (1994) outlined the basic progression of intentional communication and found that children demonstrated the following development: gestures, gestures paired with vocalizations, gestures and some single words, and words replacing most gestures. Finally, Thal and Bates (1988), and Thal and Tobias (1992) found that the ability to sequence gestures has a positive correlation with language comprehension ability. It appears that the use of gesture is an integral part of the transition to spoken language.

In reviewing the development of gestures, it appears they play a crucial role in a partnership of developing language and intentionality. They are the main conveyors of thought during the prelinguistic period. Gestures help a child to communicate with and regulate their world. The role of gestures in the development of play is also crucial, with regard to the physical manifestation of imagining substitutions and carrying them out. An important aspect of gesture development lies in their coordinated role with language acquisition and attainment of cognitive milestones. Furthermore, the review of gesture development lends insight into how a child's developing receptive and expressive language could be altered if gesture development was hindered by a physical impairment.

\section{Development of Intentional Communication}

Children begin to use intentional communication through gestures, which are then accompanied by vocalizations and then words (Owens, 1992). According to Bates, Camaioni, and Volterra (1975), children go through three important stages during the development of intentionality. In the first stage, prelocutionary (birth to 8 months), the child 
uses such gestures as hiding his/her face, playing peek-a-boo, and extending his/her arms to be picked up. In the second stage, illocutionary (8-12 months), the child displays a full range of gestures which show an understanding of the function or object purpose for toys or household goods, such as holding a play phone to his/her ear (Bates et al., 1975). The third stage, locutionary (12+ months), words and gestures are used together and eventually words replace most gestures (Bates et al., 1975). The gestures that are used at the beginning of intentional communication consist of reaching or pointing for a desired object, extending the open hand to offer an object, or showing an object with an extended tightly closed hand (Owens, 1988). After a child has pointed and vocalized in reference to the object, the parent usually acts upon the object for the child. This begins the important association of gesturing and vocalizing, which is paired with parent action (Owens, 1988).

Wetherby, Cain, Yonclas, and Walker (1988) studied intentional communication in normally developing children from 11 to 14 months old. They found that a child's rate of communicative acts (CA) per minute increased from the prelinguistic stage (PLS) to the multiword stage (MWS). A correlation was found between a child's mean length of utterance (MLU), size of lexicon, and communicative rate. Not only did the subjects use a variety of different CAs, but gestures decreased as lexicon size increased.

Owens (1988) listed joint reference, joint action, and turn taking as essential interaction behaviors which serve as building blocks upon which vocabulary, pragmatic skills, gestural, and vocal development are built. During joint reference behavior, which begins in the prelinguistic stage, the parent and the child share a common focus, usually an object, which they both look at (Owens, 1988). The PLS is the time period in which the child communicates via gestures and vocalizations and is not using words to communicate. 
This can be very important for the development of naming, deictic terms (spatial and temporal), turn taking skills, and gesturing/indicating (Owens, 1988). Owens (1988) states that joint action behaviors are established when the parent provides "routinized actions which provide a repetitive structure in which language can be analyzed." These "routinized actions" are the daily repeated games that the parent and the child participate in (e.g., pattycake or peek-a-boo) (Owens, 1988). Bruner (1978, cited in Owens, 1988) reports that these interactions allow the child to practice role shifting, taking turns, coordinating signaling to the partner, and acting upon objects.

Joint reference and joint action are the perfect experiences in which turn taking can be practiced and refined. For example, a child may look at an object, reach for it, and vocalize. The parent in turn looks at the object, gets the object for the child, and, usually, begins to talk about the object. The parent's modeling of waiting and watching while the child communicates and their subsequent response to the child's behavior are very important for development of turn taking behaviors (Owens, 1988).

\section{Development of Phonological Skills from Birth to Five}

At 7 to 12 months, children practice babbling in the consonant-vowel (CV) form and then begin reduplicated babbling (Owens, 1988). Consonant repertoires from 7 to 12 months usually contain labial and alveolar plosives (e.g., $/ \mathrm{p} /, / \mathrm{b} /, / \mathrm{t} /$, and $/ \mathrm{d} /$, the nasals, and the glide /j/) (Stark, 1979, cited in Fletcher \& Garman, 1986). Sander (1972) found the following development of phonemes in all word positions at the word level: at age 1 year and 5 months, $50 \%$ of children were producing $/ \mathrm{p} /, / \mathrm{h} /, / \mathrm{n} /, / \mathrm{b} /, / \mathrm{m} /$, and $/ \mathrm{w} /$ correctly. In a review of the literature, Owens (1988) found that vowels are acquired first and then consonants. He also stated that children acquire consonant sounds in the initial position in 
words first, as well as the following succession of sound classes: nasals, glides, and plosives. The first developing sound positions are usually glottals and labials (Owens, 1988). Stoel-Gammon (1987) found that half of 2-year-olds exhibited the following patterns: (a) production of 9 to 10 different consonants in word initial position for labial, alveolar, and velar sounds, and 9 to 10 different consonants for classes of sounds (stop, nasal, fricative, and glide), e.g., /b/, /t/, /d/, /k/, /g/, /m/, /n/, /h/, /w/, /f/, /s/; (b) production of 5 to 6 different consonantal phones in word final position, e.g., consonants that occurred in $50 \%$ of the inventories included $/ \mathrm{p} /, / \mathrm{t} /, / \mathrm{k} /, / \mathrm{n} /, / \mathrm{s} /, / \mathrm{r} /$; and (c) while half of the children produced consonant clusters in the form of initial CCV-, and final -VCC, a majority of children demonstrated a range of syllable shapes, i.e., CV, CVCV, CVCVC.

Sander (1972) found that by age $2,50 \%$ of children were producing $/ \mathrm{g} /, / \mathrm{f} /, / \mathrm{d} /, / \mathrm{t} /$, $/ \mathrm{n} /$ correctly. At age 2 years and 5 months, $50 \%$ of children were producing $/ \mathrm{j} /, / \mathrm{s} /, / \mathrm{r} /$, and $/ 1 /$ and $/ v /$ was produced by age 3 . At age 3 years and 5 months, $50 \%$ of children were producing /S/, /tS/, and /z/. From a phonological perspective, Stoel-Gammon (1991) found the following patterns in the phonological acquisition of 2 to 3 -year-old children. Her review of the literature revealed that at least $50 \%$ of what a child says at the age of 2 can be understood by a stranger (Coplan \& Gleason, 1988). During this time period, the phonological system changes considerably with regard to the number of different sounds produced, types of syllable and word shapes that occur, and the accuracy of production. There is also an increase in overall intelligibility (Coplan \& Gleason, 1988).

Children acquire the remaining classes of sounds in the following order: liquids, fricatives, and affricates (Owens, 1988). The remaining positions of sounds are usually acquired in the following order: velars, alveolars, dentals, and palatals (Owens, 1988). 
Sander (1972) found the sounds $/ \Theta /, \not / /, / z /$ all came in from age $4+$ years to $6+$ years. Templin (1957, as cited in Creaghead, Newman, \& Secord, 1989) found that $75 \%$ of children were able to say the following double consonant blends at age 5: initial /fl/, /str/, medial /j/, and final /rp/, /lb/,/rd/,/rf/, /rn/. However, Owens (1988), stated that consonant clusters and blends are not usually acquired until 7 or 8 years of age (e.g., /skr/, /spl/, /tr/). These patterns indicate that children progressively acquire more phonemes and more complex phoneme patterns as they develop.

\section{Lexical Growth and Category Development}

Goldfield and Reznick (1990) found that a majority of children experience a 3month period, at around age 1.2 years, in which lexicon count skyrockets and a large percentage of their words are categorized in the noun class. Benedict (1979) found that children began comprehending words at around 9 months, and that production, generally, began at 12 to 18 months. This information supported the theory that comprehension precedes production, since comprehension acquisition was twice that of production acquisition. Benedict (1979) also found, for both comprehension and production during this beginning language development, that the child is learning several classes of words. In assessing the categorical distribution of words for both comprehension and production, nominals and action words were the two largest groups of words.

Some children do not experience a noun explosion but gain new words at a steady pace, and may have a wider range of word classes represented in their lexicons (Goldfield \& Reznick, 1990). Rescorla (1980) investigated category development in children 1.0 to 1.6 years of age. She found that children demonstrated the following patterns: (a) over extension of a word when labeling like items; (b) a higher level of acquisition of words for measures 
of comprehension; (c) different amounts of words acquired within common word category selection; and (d) use of superordinate words. Benedict (1979) found that children tend to use non-action words when they are acting upon something, and used action words to initiate actions.

Coplan and Gleason (1988) found that the typical 2-year-old communicates primarily using content words (nouns, adjectives, and verbs). Rescorla (1980) found that children have a basic understanding of category development at age 2. Dale and Thal (1989, cited in Stoel-Gammon, 1991) found that an average toddler, at age 24 months, has a productive vocabulary of over 300 words. At age 3, a child has an average vocabulary of 1,000 words and an MLU of 3.1 morphemes (Wehrabian, 1970). At age 4, a child has an approximate vocabulary of 1,500 to 1,600 words and, at age 5, a child has around 2,200 words ( Owens, 1988; Wehrabian, 1970). These studies show a consistent and steady growth in a child's lexicon.

\section{Communication and Cognition in Children with Cerebral Palsy}

Since the present study will be focusing on the language and gestures of children who have $\mathrm{CP}$, as reported by parent questionnaire, past research which looks at daily interaction patterns, and the influences on language and physical interaction may give an insight into what may be the average or typical communicative environment for a child with CP.

Redditi-Hanzlik and Stevenson (1986) looked at the verbal and physical interaction of mothers with their infants (age 8 to 32 months) who were mentally retarded, retarded with $\mathrm{CP}$, or non-retarded. Parents and their children were videotaped during free play so 
that a content analysis of their utterances could be completed. They found that the mothers of the children with mental retardation and CP demonstrated more communications and higher rates of physical contact. The parents were more directive in their communication with infants who were retarded or had CP. The infants with CP were less responsive, more compliant, and less independent when compared to the other groups. In addition, the infants with CP demonstrated an overall lower level of behavior and were less verbal (RedditiHanzlik \& Stevenson, 1986).

Another study by Redditi-Hanzlik (1990) also looked at two groups of subjects: mothers and their children with $\mathrm{CP}$, and mothers and their typically developing children (age 8 to 32 months). Again, Redditi-Hanzlik looked at verbal interactions but focused on the nonverbal interactions. It was reported that mothers of children with $\mathrm{CP}$ were more verbally and physically directive, and engaged in fewer positive behaviors in their initiation and response communication patterns. The mothers and infants with $\mathrm{CP}$ engaged in fewer face-to-face interactions, but had higher physical interaction overall. These results were interpreted as having negative implications for the verbal and non-verbal interactions of this population. Specifically, joint referential types of behaviors demonstrated by mothers and their infants with CP may be affected (Redditi-Hanzlik, 1990).

O'Brien and Andresen (1983) looked at some of the unique elements of communication interaction for parents of a child with CP. The authors noted that, as a result of the CP, children may give altered or deficient prelinguistic stimuli to their parents. This in turn may affect a parent's communicative output and interest in language interaction with their developing child (O'Brien \& Andresen, 1983). Also, a child's decreased mobility or motoric skill may inadvertently decrease the quality of their experiences in the world. This 
need not happen if parents structure and build these opportunities with direct presentation of sensory information. For example, if a child is taken to a garden to watch people plant seeds and hears the vocabulary used for this situation, this is a learning experience. However, if a child is taken to a garden and someone sticks the child's feet in the cold dirt and allows $\mathrm{him} / \mathrm{her}$ to smell and touch it, they are gaining sensory information along with new vocabulary and the experience becomes much more enriching (O'Brien \& Andresen, 1983). The authors recommended that parents use a highly interactive style in multiple settings for early communication. They also stressed the family's critical role in providing real life interactive experiences with respect to their involvement in the early communicative and cognitive gestalts of the child.

Light, Binger, and Kelford-Smith (1994) assessed the story-reading interactions of preschool children with $\mathrm{CP}$ who use AAC systems and their mothers. A majority of the mothers dominated verbal interactions during reading, while their children forfeited many communicative opportunities. Parents did not integrate use of their child's AAC systems, nor did they use positioning with their child which would maximize face-to-face communication during storybook reading (i.e., a very important feature for children who use eye gaze to communicate). Alarmingly, child interaction did not increase while reading familiar storybooks, which has been documented as an important behavior among typically developing children (Light et al., 1994; Snow \& Ninio, 1986, cited in Teal \& Sulzby, 1986). Nevertheless, a few of the mothers of the children with CP did show a variety of communicative behaviors by labeling or talking about pictures, relating their child's experiences to the text, or asking open-ended questions. A few of the children with CP 
demonstrated a wider range of communicative attempts than their peers by labeling and commenting on pictures in the book, pointing to pictures, and turning pages.

Based upon the available literature, it appears that CP may inadvertently cause some negative effects on some of the communication interactions of the parent-child dyad (O'Brien \& Andersen, 1983). Parents appear to have much more physical interaction, more directive verbalizations, and less verbal interaction overall with children who have CP. Children with CP were less responsive to parental input and less independent (RedditiHanzlik \& Stevenson, 1986). The caregiver-child interactions during literacy events were different than those of typically developing children. It appears that these differences could have negative implications for the child's development of familiarity with text, prediction, and question/answer behaviors during reading (Light et al., 1994). The researchers stated that the physical, literacy, and verbal interaction patterns for this dyad can be modified to enhance opportunities for communication and learning.

\section{Types of Cerebral Palsy and Their Effects on Communication}

Some children with CP may not have physical limitations in the development of their speech musculature, while others may have accompanying dysarthria, which paralyzes or greatly weakens speech muscles (Hardy, 1983). Furthermore, children with CP may have paralysis or no functional use of one or more of their limbs, which could preclude the use of gestures during play interaction (Hardy, 1983). Lastly, brain damage may be a compounding factor that might affect language and gesture processing or production centers, reducing verbal and gestural comprehension (Hardy, 1983). Therefore, it is important to 
review the different types of $\mathrm{CP}$ and the common effects that may inhibit language and gesture development.

\section{Types of Cerebral Palsy}

Adler (1975) outlines the major types of $\mathrm{CP}$, their probable site of lesion, and the main characteristics/symptoms of each type. Spastic CP, which has the highest incidence rate, is a result of damage to the motor cortex, and may be characterized by an overall muscle stiffness. It may affect all four limbs (quadriplegia), only one side of the body (hemiplegia), primarily the lower half of the body (paraplegia), or both arms or both legs (diplegia) (Adler, 1975). Although the child's movements are eventually accurate, the movements are slow and laborious (Adler, 1975). A challenging feature of this disorder is that the antagonistic and reciprocal muscle groups may contract simultaneously. Adler (1975) emphasized that articulation may be severely impaired, precluding the use of words or sentences as a primary mode of communication.

Athetoid CP or dyskinesia is characterized by involuntary writhing or jerky movements while in a conscious state (Adler, 1975). Most of these children will develop tension athetosis in an effort to counteract these movements (Adler, 1975). Athetoid CP has the second highest incidence rate and is caused by lesions to the extra-pyramidal system. There are several severity levels of athetosis depending on the type and site of the lesion, which range from mild to serious constant, rapid, involuntary motion (Adler, 1975). The speech musculature may be affected by the movement disorder in most cases, since speaking involves conscious voluntary precise movement (Adler, 1975).

CP involving rigidity, ataxia, or tremor is not as prevalent as spastic or athetoid CP. People with rigidity CP have extremely slow movements and have great difficulty extending 
their extremities as a result of continual contraction of muscle groups (Adler, 1975). Ataxic $\mathrm{CP}$ is characterized by a poor sense of balance, as well as uncoordination among muscle groups. This is a result of damage to the cerebellum, which interrupts feedback from flexor and extensor muscle groups (Adler, 1975). Lastly, tremor CP or shaking palsy is characterized by tremors (shaking back and forth rhythmically) in the extremities that affect the child as soon as he/she is old enough to use his/her muscles in any way (Adler, 1975).

\section{Effects on Communication}

Hardy (1983) outlines the major impacts that CP may have on the speech-producing musculature. Spastic and athetoid CP can be the result of lesions in the upper motor, lower motor, or extrapyramidal systems (Hardy, 1983). The following speech-producing musculature and their functions may be affected on a continuum from mild to severe: (a) the respiratory system, i.e., breath support for speech; (b) the laryngeal system, i.e., voicing (subglottal pressure) and breathing; (c) coordination and function of the articulators, i.e., lips, tongue, mandible, and soft palate; (d) intraoral pressure, i.e., insufficient closure of the mouth or velopharyngeal mechanism; and (e) postural support system for speech, i.e., neck and head looking down and not sitting up straight (Hardy, 1983). The respiratory system may be affected in many ways, involving basic functioning and coordination of the internal intercostal muscles, external intercostal muscles, and abdominal and thoracic muscle groups, which govern abdominal control (Hardy, 1983). This deficiency has obvious implications for proper breath support for loudness, stress, and the smooth regulation of airflow during speech. The function and coordination of the laryngeal mechanism may also be affected, which is an important system for prosodic and basic vocal qualities of speech, e.g., fundamental frequency, stress, timing, and voicing (Hardy, 1983). The main articulators - 
the tongue, lips and jaw - may not show coordinated movement patterns or may show imprecise movements and/or slow laborious movements (Hardy, 1983). The coordinated actions and function of the velopharyngeal port, which is a highly important system for controlling intraoral air pressure for plosives and nasals, may be affected, along with the pharyngeal wall constrictors important in swallowing (Hardy, 1983).

Mysak (1980) looked at the effects that CP may have on basic listening and speech postures, as well as hand and speech movements (breathing, voicing, and articulation). These are all precursory movements which are important to the development of auditory, respiratory, gestural, pragmatic, and articulatory skill mastery. Mysak's belief is that children with CP lack many of the rudimentary or reflex responses which are essential in the development and function of future skilled speech development. Disintegration of protective reflexes in the larynx and mouth may have a negative effect on the development of voicing, pressure sounds, and labial and lingual sounds in speech (Mysak, 1980). Paralysis or incomplete innervation of the vocal cords will also affect voicing and breathing patterns.

Disintegration of basic hand movements has negative implications for the development of feeding, gestures, and signing (Mysak, 1980). There may be a delay or absence of arm support, arm balance reactions, and coordinated hand-to-arm movements (e.g., hand-to-mouth feeding movements) (Mysak, 1980). Some children with CP have difficulty in developing and establishing the basic speech postures of the head, neck, and torso which are essential elements to any coordinated movements of speech. Eventually, this puts these children at an added disadvantage when trying to communicate (Mysak, 1980). Hearing loss in children with $\mathrm{CP}$ is reported at an incidence rate of $20 \%$ and may be 
sensorineural, conductive, or both. This may have an effect on the child's perception of incoming language due to insufficient or altered sounds (Mysak, 1980).

Dysarthria may be present in the muscles of the mandible, lips, and tongue, and may cause either severe unintelligibility or completely wipe out the child's speech communication system. Dysarthria has been found at an prevalence rate of $31 \%$ to $59 \%$ of children with CP (Mysak, 1980). The velopharyngeal closure mechanism may be affected, and dystrophy or hypertrophy of the muscles in the soft palate may result in hypernasality or hyponasality (Mysak, 1980).

Assessment of Individuals with Cerebral Palsy Who Are Nonspeaking

This section presents research that addresses the assessment of nonverbal intelligence and language for people with $\mathrm{CP}$ who are nonspeaking. A review of the current methods used to assess these areas is necessary in order to consider the validity of the results and determine the current standards in these areas.

\section{Assessment of Nonverbal Intelligence}

Johnson-Martin et al. (1987) outlined and critiqued the three current approaches used in the psychological assessment of the child who is nonspeaking and physically handicapped. They found that the following procedures were used to assess nonverbal intelligence of children with $\mathrm{CP}$ who are nonspeaking: (a) standardized tests which do not have norms for this population; (b) modifications of standardized tests, which then make the results invalid for interpretation; and (c) standardized tests which have been designed and normed for this population. There are several problems that are inherent in assessing the intelligence of children who are nonspeaking. Johnson-Martin et al. (1987) cite the 
following reasons as to why there are so many problems with assessing cognitive functions of children who are nonspeaking: (a) the tests have been standardized on typically developing children and should not be used to assess the abilities of children who have physical handicaps or who have not developed with an intact sensory or motor system; (b) a child's output ability may be confused with their intellectual ability; (c) most tests which are accepted measures of IQ require speech or fine motor coordination when responding to test stimuli; and (d) the available tests that do not require verbal or motor responses measure a limited number of cognitive abilities and provide norms only for a restricted age range.

In addition, the following are negative structural aspects of tests currently used to assess children who do not speak: (a) time constraints; (b) the proximity of the test items is too close for an accurate response; (c) appropriateness of test items to the life of a physically handicapped child; (d) limited age ranges; (e) incomplete assessment of the full range of cognitive skill areas; and (f) modifications of the existing standardized test nullify the results. It appears that the valid assessment of children with $\mathrm{CP}$ who are nonspeaking has some obvious obstacles.

\section{Assessment of Language}

Assessing the language skills of people who are nonspeaking can also be challenging. Since the subjects are nonspeaking, an AAC system, pointing, or eye gaze must be used as a response mode to test stimuli, instead of verbalizing. Therefore, assessing people with severe $\mathrm{CP}$ is often a time-consuming endeavor because selecting test answers can be a laborious process (Beringer \& Gans, 1986). Also, the test picture plates may need to be modified because the range of motion for the arms/hand may be wider. For subjects who use eye gaze, pictures may need to be enlarged to show greater resolution because their 
peripheral vision may be limited due to restricted head and neck movement/positions. Furthermore, as with many cognitive assessments, these standardized tests have been normed on people who are speaking and do not have physical disabilities (Beringer \& Gans, 1986).

Parent Report Instruments: Construction, Reliability, and Validity

Since there are numerous problems with assessing children with $\mathrm{CP}$ in a traditional fashion, the construction, reliability, and validity of alternative methods should be explored. One of these methods is the use of parent questionnaires, such as the MacArthur Communicative Development Inventory: Words \& Gestures.

Dale, Bates, Reznick, and Morisset (1989) reviewed the parameters which make up a successful parent report and conducted a study which assessed the validity of such measures. Specifically, they studied Part I of the Early Language Inventory (ELI), a predecessor of the MacArthur Communicative Development Inventory: Words \& Gestures. The authors stated that a parent questionnaire should address current behaviors only, because parents may have trouble recalling all of what was said or understood by their child in the past stages of development. A parent questionnaire should be provided in a recognition format (i.e., lists of words or gestures are provided). A recognition format makes it easier for the parents to fill out the questionnaire because they do not have to recall all the possible words the child has said. Fenson et al. (1993) state that a parent questionnaire is not uniformly accurate, because of parent bias and limitations due to space constraints. Therefore, parent questionnaires are best used in collaboration with several 
other assessment tools (e.g., standardized tests, observations, or language samples).

Rescorla (1991) found parent report instruments to be successful for the following reasons:

(a) a recognition type format is used; (b) the cost-effectiveness; (c) the speed in attaining the information; and (d) the information is based on experience in multiple settings with the child over an extended period of time.

Dale et al. (1989) conducted a study to assess the validity and reliability of the ELI when compared with language samples and the Bayley Mental Development Index (BMDI) (Bayley, 1969) for children age 18 to 20 months. They looked at the language of children from several different geographical locations who were full-term, pre-term, and precocious language learners, as well as children considered at social risk due to financial or environmental factors. The information attained was used to provide norms for the ELI vocabulary checklist. The ELI was found to have a high validity $(r=.63)$ with the BMDI, particularly on the expressive language section. The authors concluded that this survey was useful as a parent report instrument, emphasizing its potential when used as part of a battery of screening tests or in research projects (Dale et al., 1989). The ELI was an earlier version of what is now called the MacArthur Communicative Development Inventory: Words \& Gestures.

Fenson et al. (1993) have assessed the validity and reliability of the MacArthur Communicative Development Inventory: Words \& Gestures in several studies. They found that it has high internal consistency and test-retest reliability, both revealing correlations of $r$ $=.8$ to $r=.9$. Since the study contained a large number of subjects, the standard deviation was small enough that there is a $95.5 \%$ confidence band for use when interpreting scores. The MacArthur Communicative Development Inventory was normed on an acceptable level 
of male/female ratio, but fell short of the national percentages for African-Americans, as well as surveying a majority of parents who had an education level of a college degree (Fenson et al., 1993). Therefore, the authors warn that clinicians should use caution when interpreting the scores of children whose families are considered minority groups and/or to be in a low socioeconomic/low educational level.

Rescorla (1981, cited in Fenson et al., 1993) reviewed the MacArthur Communicative Development Inventory and the Language Development Survey (LDS), two parent survey instruments designed to help detect a child with language delay. Rescorla (1991) cites a study conducted by Dale (1991) in which the MacArthur Communicative Development Inventory: Words \& Gestures showed a correlation of $r=.73$ with the Expressive One Word Picture Vocabulary Test (Gardener, 1979). Advantages of the survey include the fact that it was normed on different socioeconomic levels, full-term versus preterm children, and can be used with language delayed, normal, and precocious children. Terrell and Schwartz (1988) stated that the MacArthur Communicative Development Inventory: Words \& Gestures is an excellent tool for assessing actions and gestures in infants who have no expressive language or are language impaired. Also, Rescorla (1991) pointed out that the survey has been used in many different research studies, was constructed by senior researchers, and covers a wide range of geographical areas, as well as a large sample size. Another positive note was the comprehensive nature of the survey, which makes it "especially useful in providing vocabulary by form or class" (Rescorla, 1991, p. 19). It appears that parent questionnaires, such as the MacArthur Communicative Development Inventory: Words \& Gestures, are reliable and valid assessment measures. 
The fact that there are no parent questionnaires normed on children with $\mathrm{CP}$ is unfortunate. This study may show if such a tool would be useful or if existing standardized tools can be adapted in a closest-fit model. Parent questionnaires have proven to be respectable tools when used to collect information on language and gestures. However, they may have some inherent weaknesses, such as parent bias, incomplete amount of items, or the parent misunderstanding the written directions (Fenson et al., 1993). In addition, parent bias may be more of an issue when considering parental interpretation of the language comprehension and gesture production of a child who is handicapped and nonspeaking.

\section{Summary}

Having reviewed the normal development of cognition, speech, vocabulary, intentionality, categorization, and gestures, it appears there is an interrelatedness of many of these areas. As a child develops cognitively, intentionality, gesturing, speech, vocabulary, and the ability to categorize words also develops. In children with $\mathrm{CP}$, these areas may be delayed or completely wiped out. Since these areas do not develop in isolation, each person with CP could end up with a unique profile of strengths and weaknesses with regard to communication. Several articles were also reviewed in which the assessment of cognitive and language skills, as well as the interaction patterns of children with CP were covered. This information allows one to see the complexities involved in assessing the child with CP who is nonspeaking. The language assessment of people with CP who are nonspeaking in particular shows that each person with CP develops a unique profile of language strengths and weaknesses in the areas of spelling, reading, and receptive language (Beringer \& Gans, 
1986). The patterns of development that were found and implications for intervention are extremely important for understanding the needs of this population.

Since there is limited information pertaining to the language and gestures of children that have $\mathrm{CP}$, it is clear that more research is needed in attaining descriptive data on these areas for preschool children. In the literature review, several researchers found that parent report can be an efficient reliable method for gathering information on language and gestures (Rescorla, 1991). The parent questionnaire allows a researcher to draw from the parent's multiple experiences with language in a naturalistic setting over an extended period of time (Rescorla, 1991). Parent questionnaires have shown high correlations with several standardized measures, as well as other traditional assessment methods (i.e., observation, language sample, and parent interview) (Fenson et al., 1993). Since there is not a parent questionnaire normed for children with CP, the MacArthur Communicative Development Inventory: Words \& Gestures was chosen to assess the language and gesture skills of children with $\mathrm{CP}$ in the study. The protocol will be used to gather descriptive data on word and phrase comprehension and to answer the following research questions:

1. Do children who are nonspeaking and have $\mathrm{CP}$ have a significantly different mean score for phrases comprehended than children who are speaking and have $\mathrm{CP}$, as assessed using the MacArthur Communicative Development Inventory: Words \& Gestures?

2. Do children who are nonspeaking and have $\mathrm{CP}$ have a significantly different mean score for understood words than children who are speaking and have $\mathrm{CP}$, as assessed using the MacArthur Communicative Development Inventory: Words \& Gestures? 
3. Do children who are nonspeaking and have CP have a significantly different mean score for early gestures than children who are speaking and have $\mathrm{CP}$, as assessed using the MacArthur Communicative Development Inventory: Words \& Gestures?

4. Do children who are nonspeaking and have CP have a significantly different mean score for later gestures than children who are speaking and have $\mathrm{CP}$, as assessed using the MacArthur Communicative Development Inventory: Words \& Gestures?

5. Do children who are nonspeaking and have $\mathrm{CP}$ have a significantly different mean score for total gestures than children who are speaking and have $\mathrm{CP}$, as assessed by parent report using the MacArthur Communicative Development Inventory: Words \& Gestures? 


\title{
CHAPTER III
}

\section{METHODS AND PROCEDURES}

\author{
Methods
}

\section{Subjects}

The 17 subjects, 6 females and 11 males, in the present study were recruited via telephone calls, word-of-mouth, and posters from a variety of sources (local hospitals, early intervention programs, and personal contacts) as part of a study conducted at Portland State University Speech and Hearing Sciences Program. The following eligibility criteria was used in the selection of the participants:

1. Age between 2.0 and 6.0 years.

2. A diagnosis of CP by a medical professional; subjects may have functional speech or not.

3. English as a primary language in the home.

4. An adult in the home who can complete the questionnaire used in the study.

5. Normal hearing or hearing brought to the normal level with hearing aids (i.e., $25 \mathrm{~dB}$ H.L. detection of sounds).

6. No uncorrected visual impairments may be present in the subject.

7. Completion of a signed consent form.

8. Cognitive delays may be present in the subject. 
9. Children who are nonspeaking or speaking and use sign language as a form of expressive language may participate in the study. However, the parent will indicate if a word is signed, and these words will not be counted in the child's expressive vocabulary.

The nature of the study was explained both orally and in writing to the parents.

Each parent signed a written permission form for participation in the study. See Tables 1 through 4 for a presentation of the descriptive information gathered from the parent questionnaires for the subjects in this study.

Table 1

Subject Demographics $(N=17)$

\begin{tabular}{|c|c|c|c|c|}
\hline \multirow[b]{2}{*}{ Subjects } & \multirow[b]{2}{*}{ Mean Age } & \multirow[b]{2}{*}{ Race } & \multicolumn{2}{|c|}{ Gender } \\
\hline & & & Males & Females \\
\hline $\begin{array}{l}\text { Nonspeaking } \\
(n=8)\end{array}$ & 47 months & $\begin{array}{l}\text { 62.4\% Caucasian } \\
37.5 \% \text { No reply }\end{array}$ & 7 & 1 \\
\hline $\begin{array}{l}\text { Speaking } \\
(n=9)\end{array}$ & 46 months & $\begin{array}{l}55.0 \% \text { Caucasian } \\
45.0 \% \text { No reply }\end{array}$ & 5 & 4 \\
\hline
\end{tabular}

Table 2

Use of an Augmentative and Alternative Communication System $(N=17)$

\begin{tabular}{|l|c|c|}
\hline & $\begin{array}{c}\text { Speaking } \\
(n=9)\end{array}$ & $\begin{array}{c}\text { Nonspeaking } \\
(n=8)\end{array}$ \\
\hline Uses an AAC system & $22.25 \%$ & $50.00 \%$ \\
\hline Not using an AAC system & $55.50 \%$ & $12.50 \%$ \\
\hline No information & $22.25 \%$ & $37.50 \%$ \\
\hline
\end{tabular}


Table 3

Cognitive Status as Reported by Parent $(N=17)$

\begin{tabular}{|l|c|c|c|c|}
\hline & At Age Level & Delayed & Unknown & No Information \\
\hline Nonspeaking $(n=8)$ & $22.2 \%$ & $33.3 \%$ & $11.1 \%$ & $33.4 \%$ \\
\hline Speaking $(n=9)$ & $37.5 \%$ & $25.0 \%$ & $00.0 \%$ & $35.5 \%$ \\
\hline
\end{tabular}

Table 4

Percentages of Subjects Who Received Speech and Language Intervention $(N=17)$

\begin{tabular}{|l|c|c|c|}
\hline & Intervention & No Intervention & No Information \\
\hline Nonspeaking $(n=8)$ & $75.0 \%$ & $00.0 \%$ & $25.0 \%$ \\
\hline Speaking $(n=9)$ & $77.8 \%$ & $11.1 \%$ & $11.1 \%$ \\
\hline
\end{tabular}

\section{Instrumentation}

The MacArthur Communicative Development Inventory: Words \& Gestures questionnaire was developed for infants 8 to 16 months of age, but can be used with older populations who are language delayed or have no expressive language (Fenson et al., 1993). The norm referenced information for age equivalents was obtained based on the performance of a representative national sample of 671 infants who were typically developing. The MacArthur Communicative Development Inventory: Words \& Gestures instrument is divided into two distinct categories - Part I: Early Words, and Part II: Actions and Gestures. In Part I-A, the parent is first asked three questions which assess whether or not the child responds to language (e.g., Responds to their name being called?, Responds to "no no"?, Reacts to "There's mommy/daddy"?) (Fenson et al., 1993). In Part I- 
B the parent is asked whether or not their child understands a list of 28 common phrases, and, thus, the highest score a child can receive for this section is 28 points. Part I-C probes whether or not the child is labeling items or imitating words. In Part I-D contains different semantic categories of 396 total words, but the majority are nouns. Parents are asked to indicate whether the child produces and/or comprehends each of these words. The highest possible score for this section is 396 points for comprehension, as well as for production of words. The questionnaire allows the parent to indicate if the child "understands a word," or "understands and says a word."

In Part II: Actions and Gestures, the parent is able to indicate whether or not the child is demonstrating "a wide range of early symbolic and communicative skills" (Fenson et al., 1993). Part II-A and II-B (18 total points) assess early gestures and Part II-C, II-D, and II-E later gestures (45 total points). Part II-E of the instrument covers 63 gestures that fall into the following five categories: (a) onset of intentional communication; (b) conventionalized communicative gestures; (c) social interaction; (d) actions with objects; and (e) imitating things. Part II-F, which lists any symbolic play skills, is not considered in scoring (Fenson et al., 1993). The highest possible score for total gestures is 63 points.

In order to look at different variables in the children's lives and gather information relevant to interpretation of the results, the present investigator asked parents to volunteer the following information on the other comments section on the last page of the MacArthur Communicative Development Inventory: Words \& Gestures:

1. What type of $\mathrm{CP}$ does your child have?

2. Does your child have any accompanying syndromes, disabilities or handicaps? 
3. What is the cognitive or mental age of your child (if known)?

4. Is an AAC system being used? If so, what type?

5. Does your child have normal hearing?

6. What is your total annual household income?

7. What race is the child?

8. Has your child received speech and language treatment? If so, for how long?

\section{Procedures}

Posters regarding the study were placed at the following agencies that serve children with CP: Shriners Children's Hospital, Easter Seals, and Holliday Center. Cover letters explaining the study and consent forms for participation were distributed by speech language pathologists at these agencies to families of children who were potential subjects. A consent form was on the back side of the cover letter with a place for the parent to sign his/her name and provide a telephone number to be mailed to the researcher in a previously addressed and stamped envelope (see Appendix A). Once the envelope was received by the researcher, a telephone call was made to the family in order to assure that the child met the criterion listed in the study, to discuss the child's communication skills with the parent, and to obtain their address.

The parent was then sent a packet which contained the following: (a) directions for filling out the MacArthur Communicative Development Inventory: Words \& Gestures (see Appendix B); (b) a copy of their signed consent form; (c) the MacArthur Communicative Development Inventory: Words \& Gestures (see Appendix C); and (d) a stamped and 
addressed envelope. The parents filled out the MacArthur Communicative Development Inventory: Words \& Gestures, which takes 20 to 40 minutes, and returned it in the stamped and addressed envelope. The parents were instructed, in writing, to fill out both Part I: Early Words, and Part II: Actions and Gestures. The extent to which they filled out these sections depended on their child's abilities and primary method of communication.

The children whose parents reported expressive oral vocabularies at 19 words or less on the MacArthur Communicative Development Inventory: Words \& Gestures were considered nonspeaking, and children whose parents reported expressive vocabularies at or above 20 words on the MacArthur Communicative Development Inventory: Words \& Gestures were considered speaking.

\section{Data Analysis}

The questionnaires were hand tabulated to attain raw scores for phrase comprehension, vocabulary production, vocabulary comprehension, early gestures, later gestures, and total gestures (see Appendix D). As a second analysis, subjects were divided into two groups based on their number of words spoken on the MacArthur Communicative Development Inventory: Words \& Gestures. Those children with 20 spoken words or more were considered speaking. Those children with fewer than 20 spoken words were considered nonspeaking. Mean scores for each measure on the MacArthur Communicative Development Inventory: Words \& Gestures were calculated for each subject group. The mean scores were then compared to the scores in the MacArthur Communicative Development Inventories: User's Guide and Technical Manual (Fenson et al., 1993) that were derived from typically developing children, ages 8 to 16 months. An age equivalency was found for the mean score on each measure based on the closest score match at the $50^{\text {th }}$ 
percentile. In addition, a percentage was calculated for the number of subjects who reportedly were responding to language (Part I-A), starting to label and imitate (Part I-C), and demonstrating symbolic gestures (Part II-F) for both groups of subjects.

\section{Descriptive Statistics}

Descriptive data (mean, standard deviation, and range) on scores on the MacArthur Communicative Development Inventory: Words \& Gestures for the following scales were reported for the speaking and nonspeaking groups: (a) phrase comprehension; (b) word comprehension; (c) word production; (d) early gestures; (e) later gestures; and (f) total gestures.

\section{Inferential Statistics}

A non-parametric $t$-test equivalency (i.e., Rank Wilcoxon Sum) was used to see if a difference exists between mean scores of the speaking and nonspeaking groups for all the scales, except word production, of the MacArthur Communicative Development Inventory: Words \& Gestures. This coefficient is a non-parametric test statistic which determines if two variables are independent of each other. Non-parametric statistics were used because of the low number of subjects in the study. An alpha level for the study was set at .05 to determine if any correlations found are statistically significant. 


\section{CHAPTER IV}

\section{RESULTS AND DISCUSSION}

The purpose of this research was to obtain descriptive data (mean, standard deviation, range) on the expressive and receptive language and gesture production of children with CP who are speaking and nonspeaking and are between the ages of 2 and 6 years, via a parent report instrument (MacArthur Communicative Development Inventory: Words \& Gestures). The data were also analyzed to determine whether there were significant differences for mean receptive language (phrases and words) and mean expressive gesture production (early, later, and total gestures) between the two subject groups (children who are speaking and nonspeaking).

The research hypotheses asserted the following: The children who are nonspeaking and have CP will have significantly different mean scores for all the MacArthur Communicative Development Inventory: Words \& Gestures scales (except the expressive words measure) than children who are speaking and have $\mathrm{CP}$.

\section{Results}

\section{Children with Cerebral Palsy Who Are Speaking}

Descriptive statistics are reported in Table 5. There it can be seen that the subjects who are speaking had an average age of $3.11(S D=3.6$ months). The average number of phrases comprehended for this group was $26.5 / 28$ possible phrases. The average number of receptive words for this group was $287 / 396$ possible words. The average number of 
expressive words for this group was $181.2 / 396$ possible words. An age equivalency could not be equated for these measures using the scores of the typically developing children in the norming sample since these results were higher than the $50^{\text {th }}$ percentile at 16 months. If scores are above the $50^{\text {th }}$ percentile at the highest age level represented in the norming sample, there is a risk of underestimating or overestimating a child's skills by trying to equate an age equivalency. This means the mean scores for this group were above the average score at 16 months, but does not tell us anything more than that. The average number of early gestures for this group was $9.1 / 18$ possible gestures. This equates to an age equivalency of 12 months when compared with the scores of typically developing children. The average number of later gestures for this group was $26 / 45$ possible gestures. An age equivalency could not be equated since this result was higher than the $50^{\text {th }}$ percentile at 16 months. Therefore, this group's later gesture performance is above the mean score at 16

Table 5

Descriptive Data for Children with CP Who Are Speaking $(n=9)$

\begin{tabular}{|l|c|c|c|c|}
\hline & $M$ & $\begin{array}{c}\text { Age } \\
\text { Equivalency }\end{array}$ & $S D$ & Range \\
\hline Age (months) & 47.4 & N/A & 3.6 & $34(26-60)$ \\
\hline Phrase Comprehension & $26.5 / 28$ & NATS* & .96 & $7(21-28)$ \\
\hline Receptive Words & $287 / 396$ & NATS* & 34.8 & $310(86-396)$ \\
\hline Expressive Words & $181.2 / 396$ & NATS* & 54.6 & $372(24-396)$ \\
\hline Early Gestures & $9.1 / 18$ & 12 months & 2.0 & $18(0-18)$ \\
\hline Later Gestures & $26 / 45$ & NATS* & 5.6 & $45(0-45)$ \\
\hline Total Gestures & $35.1 / 63$ & 15 months & 7.3 & $63(0-63)$ \\
\hline
\end{tabular}

*NATS $=$ Not able to score or find an age equivalency. 
months for typically developing children. The average number of total gestures for this group was $35.1 / 63$ possible gestures. This equates to an age equivalency of 15 months when compared with the scores of typically developing children.

\section{Children with CP Who are Nonspeaking}

Descriptive data for subjects who are nonspeaking are presented in Table 6 . There it can be seen that these subjects had an average age of 3.10 years (SD 4.2 months). The average number of phrases comprehended for this group was $20.9 / 28$ possible phrases. This equates to an average age equivalency of 15 months when compared to the norms of typically developing children. The average number of receptive words for this group was 214.8/396 possible words. An age equivalency could not be equated using the scores of typically developing children since this result was higher than the $50^{\text {th }}$ percentile at 16

Table 6

Descriptive Data for Children with CP Who Are Nonspeaking $(n=8)$

\begin{tabular}{|l|c|c|c|c|}
\hline & $M$ & $\begin{array}{c}\text { Age } \\
\text { Equivalency }\end{array}$ & $S D$ & Range \\
\hline Age (months) & 46 & N/A & 4.2 & $34(35-69)$ \\
\hline Phrase Comprehension & $20.9 / 28$ & 15 months & 3.7 & $28(0-28)$ \\
\hline Receptive Words & $214.8 / 396$ & NATS* & 44.8 & $344(10-354)$ \\
\hline Expressive Words & $7.4 / 396$ & 14 months & 2.6 & $19(0-19)$ \\
\hline Early Gestures & $7.8 / 18$ & 11 months & 1.6 & $13(0-13)$ \\
\hline Later Gestures & $17 / 45$ & 14 months & 2.5 & $23(8-31)$ \\
\hline Total Gestures & $24.9 / 63$ & 13 months & 3.9 & $33(11-44)$ \\
\hline
\end{tabular}

*NATS $=$ Not able to score or find an age equivalency. 
months. This means their mean performance for receptive words is above the mean performance at 16 months for typically developing children. The average number of expressive words for this group was $7.4 / 396$ possible words. This equates to an age equivalency of 14 months when compared with scores for typically developing children.

The average number of early gestures for this group was $7.8 / 18$ possible gestures. This equates to an age equivalency of 11 months when compared with the scores of typically developing children. The average number of later gestures for this group was $17 / 45$ possible gestures. This equates to an age equivalency of 14 months when compared with the scores of typically developing children. The average number of total gestures for this group was $24.9 / 63$ possible gestures. This equates to an age equivalency of 13 months when compared with the scores of typically developing children.

\section{Statistical Significance}

The Wilcoxon rank sum equation, a two tailed test, was used to compare mean performance between the different groups of children (speaking and nonspeaking). Again, non-parametric statistics were used as a result of the low number of subjects in each group. An alpha level of .05 was used to test the statistical significance. The mean scores for the nonspeaking children were significantly different from the mean scores of the speaking children on all five scales of the MacArthur Communicative Development Inventory: Words \& Gestures.

\section{Trends for Both Groups}

All of the children (speaking and nonspeaking) had $100 \%$ positive responses for Part I-A, First Signs of Understanding. This section probes whether or not the child is 
responding to language. However, in Part I-C, Starting to Talk, the speaking children had a $100 \%$ positive response rate for attempting to imitate words, while the nonspeaking children had $50 \%$ positive response rate. In Part I-C, the speaking children group had a $66.9 \%$ positive response rate for labeling items, and the nonspeaking group of children had a $25 \%$ positive response rate. Part II-F, a question that required a yes/no response for symbolic gestures, showed the greatest difference between the two subject groups. The speaking group of children had a positive response rate of $66.7 \%$, while the nonspeaking group of children had a $0 \%$ positive response rate (see Table 7 ).

Table 7

Responding to Language, Starting to Talk, and Symbolic Gestures $(N=17)$

\begin{tabular}{|l|c|c|c|c|}
\hline Subjects & $\begin{array}{c}\text { Responding } \\
\text { to Language }\end{array}$ & Imitating & Labeling & $\begin{array}{c}\text { Symbolic } \\
\text { Gestures }\end{array}$ \\
\hline Nonspeaking $(n=8)$ & $100 \%$ & $50 \%$ & $25 \%$ & $0 \%$ \\
\hline Speaking $(n=9)$ & $100 \%$ & $100 \%$ & $66.9 \%$ & $100 \%$ \\
\hline
\end{tabular}

\section{Discussion}

The nonspeaking children group attained between 11 to 15 month age equivalencies for all five measures on the MacArthur Communicative Development Inventory: Words \& Gestures when their scores were compared to typically developing children. The children in the nonspeaking group received their highest scores for receptive words, which were above the $50^{\text {th }}$ percentile at 16 months for typically developing children. Early and total gesture age equivalencies were 12 and 15 months, respectively, for the children who are nonspeaking. 
Both groups were extremely delayed in early and total gestures when compared to typically developing children. However, the speaking group scored above the $50^{\text {th }}$ percentile at 16 months for later gestures, while the nonspeaking group had an age equivalency of 14 months. The children who are speaking scored well above the $50^{\text {th }}$ percentile at 16 months when compared to the norms for typically developing children for phrase and word comprehension and later gestures. Both groups showed high percentages for responding to language, but showed significant differences in imitating and labeling with words, and symbolic gesture production.

Perhaps the reason that the children with $\mathrm{CP}$ who are speaking have larger receptive vocabularies is because they may be receiving more language stimulation than their nonspeaking peers. It is widely accepted that most young children have higher receptive vocabularies than expressive vocabularies. As a child's receptive vocabulary grows, so does his/her expressive vocabulary. Thus, when a child is able to talk and use words in certain contexts, he/she tends to pick up new words through verbal interactions with peers and caregivers. There is some evidence that many parents talk at a level that they believe their child will understand (Owens, 1988). It is also through verbal practice, paired with parental modification and modeling, that children refine their correct use of words and, thus, learn multiple meanings and associations of words (Owens, 1988).

Perhaps it is more difficult for the parents of the children with $\mathrm{CP}$ who are nonspeaking to figure out what words their child understands. This may in turn affect verbal output to their child. A child with CP who is nonspeaking may not be able to give the parent the necessary responses which would make the parent stop and focus on a word with repetitive examples, personal experiences, or physical demonstrations. 
On the other hand, the MacArthur Communicative Development Inventory: Words \& Gestures was not normed for children who have physical impairments, nor for an age range as high as 2.0 to 6.0 years. Again, the MacArthur Communicative Development Inventory: Words \& Gestures was not sensitive enough to tease out an age equivalency for both subject groups for the measure of receptive words. Therefore, this tells us that both groups performed above the $50^{\text {th }}$ percentile at 16 months for typically developing children, but nothing else. Perhaps another parent questionnaire with an older age range will need to be used to assess receptive word knowledge for both groups of subjects.

The ages of the children in the study ranged from 2.2 to 5.11 years. Age is an important factor when looking at the performance for the six scales of the MacArthur Communicative Development Inventory: Words \& Gestures. It is commonly accepted in the field of speech and language pathology that children without language delays will attain more receptive and expressive vocabulary words as they get older. Vocabulary comprehension usually exceeds vocabulary production, as children tend to understand a word first and then attempt to use it (Owens, 1988). Similarly, certain types of gestures are associated with certain age groups and tend to develop chronologically (Haynes \& Shulman, 1994). Therefore, it makes sense to look at performance on the different MacArthur Communicative Development Inventory: Words \& Gestures scales for the children who are speaking and nonspeaking at different ages by year. In this way, if performance increases by age it should show a linear relationship. Also, if there are outliers in the scatter plot, other factors could be analyzed to see what else could be influencing the performance of specific children. The factors that look like they are producing the outliers, as well as variables 
which suggest a pattern or linear relationship, should indicate areas of interest for future research.

When looking at the scatter plot for phrase comprehension and age, there was no relationship for either the speaking group or nonspeaking group, and, thus, it was not posted. However, as displayed in Figure 1, the speaking group shows a steady incline in the number of receptive words as age increases. The score of the 5-year-old subject in the speaking group appears to decrease slightly, when compared to the performance of the 3 and 4-year-old children. Upon further analysis, it was noted that this subject's parent reported a mild delay in cognitive development. The nonspeaking group did not show any sort of pattern when these two factors were compared.

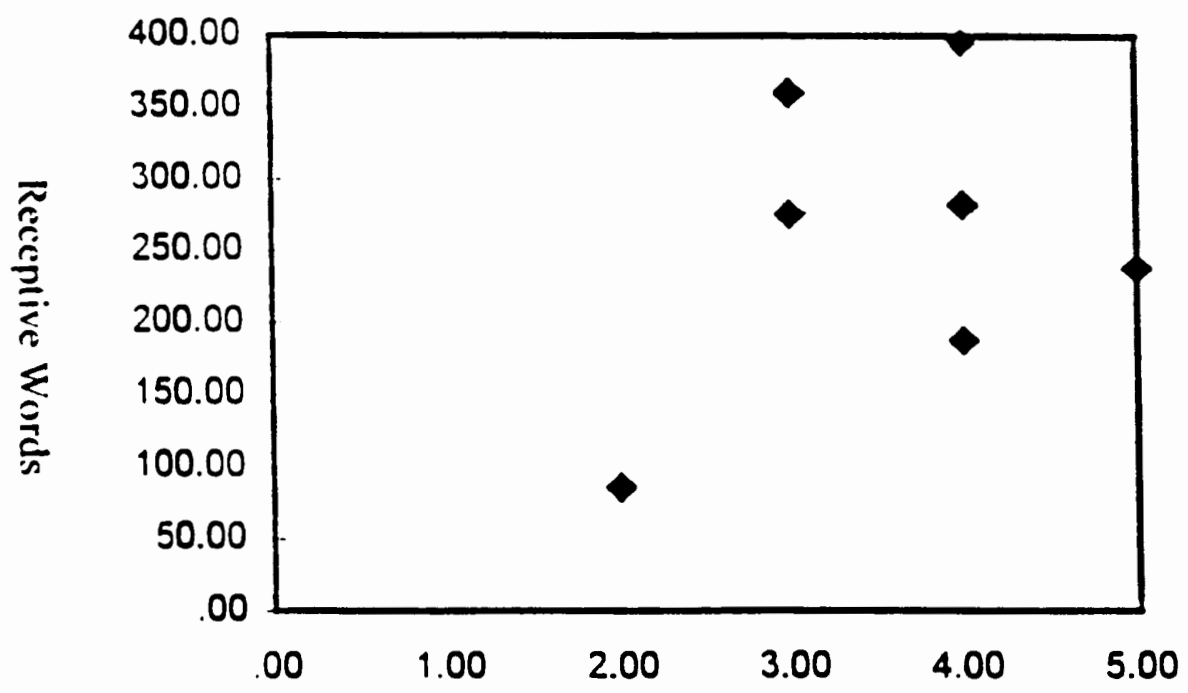

Age

Figure 1

Raw Scores by Age for Number of Receptive Words in Children with CP Who Are Speaking $(n=9)$ 
Neither group demonstrated any kind of relationship when age was compared with expressive words. Perhaps the speaking group would have demonstrated more of a linear relationship if the parameter of 20 spoken words for inclusion in the speaking group would have been higher. There were two 3-year-old children and two 4-year-old children in the speaking group who had fewer than 100 words. This is far below normal word production for a typical 3-year-old and obviously skewed the results.

Neither group demonstrated a relationship when comparing age to production of early gestures. In fact, both patterns appeared to indicate an inverse relationship of early gesture when compared with age. Perhaps the older children had more severe levels of CP, or were more delayed in cognitive skills.

For the speaking group, later gestures and total gestures, when compared with age, both appear to demonstrate a linear relationship (see Figures 2 and 3). One 4-year-old and one 5-year-old in the speaking group did not receive a score for early, later, and total gestures as the parents did not fill out their questionnaires completely. These scores were not taken into consideration when looking at age versus performance trends for the speaking group.

In summary, the scatter plots show that the children who are speaking demonstrated more of a linear relationship with regard to performance when receptive vocabulary and later and total gestures were compared to age in years. Some children's scores could be considered outliers, because they deviated from the overall linear pattern of performance increasing with age. The parents of these subjects reported cognitive delays. This indicates a need for future research in the area of language and gestures of children with CP without cognitive delays who are speaking. 


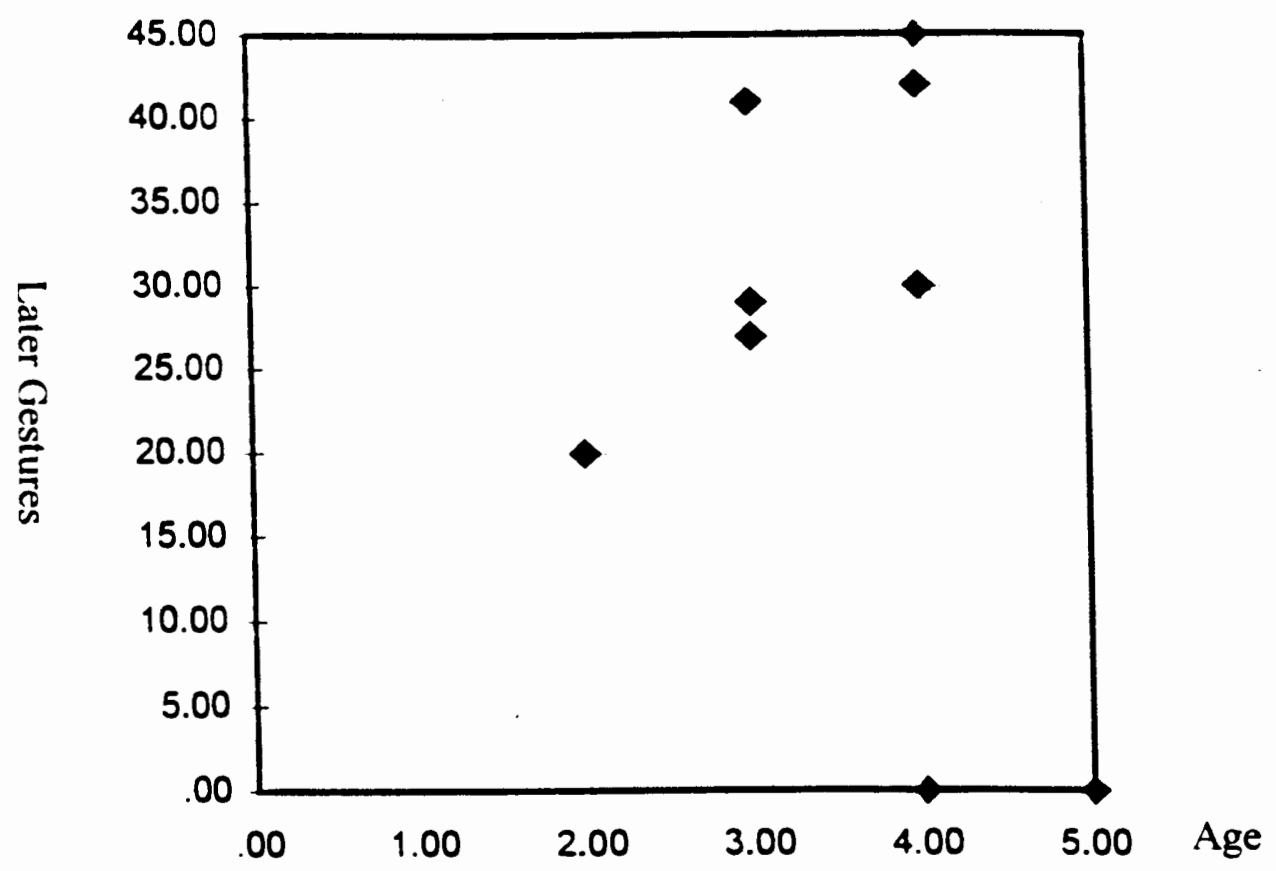

Figure 2

Raw Scores by Age and Number of Later Gestures in Children with CP Who Are Speaking $(n=9)$

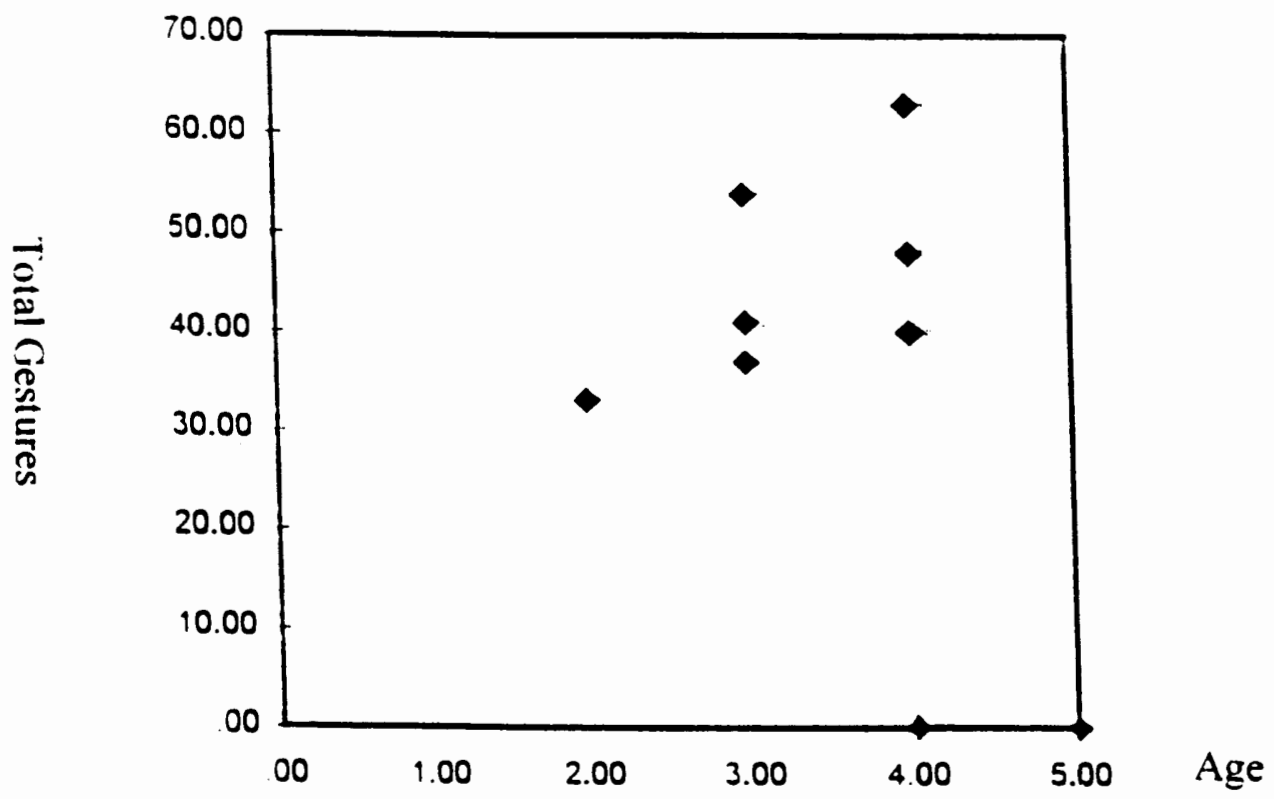

Figure 3

Raw Scores by Age and Number of Total Gestures in Children with CP Who Are Speaking $(n=9)$ 


\title{
CHAPTER V
}

\section{SUMMARY AND IMPLICATIONS}

\author{
Summary
}

Many children with $\mathrm{CP}$ will require speech and language intervention, especially if they are nonspeaking and using an AAC system (Hardy, 1983). However, there is not a body of research which attempts to gather descriptive data on the language and gestures of children with CP (Fenson et al., 1993). The first purpose of the present study was to build a small body of descriptive data on the expressive and receptive language and gesture production of children with CP via parent report. The second purpose of the study was to compare the mean scores of the children with $\mathrm{CP}$ who are nonspeaking to the children with CP who are speaking. The MacArthur Communicative Development Inventory: Words \& Gestures, a parent questionnaire developed for younger typically developing children, was selected as the research instrument for this study because it assesses expressive and receptive vocabulary, and a wide range of gestures. The subjects were recruited through several local early intervention programs, hospitals, and by word of mouth. There were 17 subjects whose ages ranged from 2.2 years to 5.11 years. The subjects had different types of $\mathrm{CP}$ and some of the subjects had cognitive delays. The data were collected from the parent questionnaires and put into tables demonstrating the descriptive and statistical analysis. The suggested trends from the study include: children who are nonspeaking attained age equivalencies at 16 months or below for all the MacArthur Communicative Development 
Inventory: Words \& Gestures scales except receptive words. The children who are speaking attained age equivalencies above 16 month level for all measures on the MacArthur Communicative Development Inventory: Words \& Gestures except early and total gestures. There were significant differences in the scores of both groups for comprehended phrases and words, and early, later, and total gesture production, beyond the $r=.05$ level of significance. Both groups were responding to language via body movements with $100 \%$ accuracy. However, the speaking children group had much higher rates of imitating and labeling, as well as demonstrating behaviors considered symbolic gestures than did the children in the nonspeaking group.

\section{Implications}

\section{Clinical}

The results of the study indicate that children 2 to 6 years old with CP who are nonspeaking performed at or below the 16 month age equivalency for all measures on the MacArthur Communicative Development Inventory: Words \& Gestures, except receptive vocabulary, when compared to the norms of typically developing children. This may suggest that, although motoric impairments or possible cognitive delays may be precluding the typical development of word production and gesture production, these children's strength, although probably not commensurate with their typically developing peers, appears to be understanding spoken words. The MacArthur Communicative Development Inventory: Words \& Gestures was not sensitive enough to tap into the age equivalency for the performance of the children who are nonspeaking for the measure of receptive words. 
Perhaps another parent questionnaire which assesses these skills at an older age level would give a more representative picture of this group's receptive word skills.

The children with CP who are speaking scored significantly higher on the receptive words scale, even though both scored above what the MacArthur Communicative Development Inventory: Words \& Gestures could measure. Caution should be used when looking at the receptive words scale of the MacArthur Communicative Development Inventory: Words \& Gestures, particularly when looking at the scores of children with CP who are nonspeaking, because some parents may overestimate how much their child is understanding. Also, both subject groups contained children who had some reported cognitive delays. These results, combined with low scores on gesture development, may also suggest that the children who are nonspeaking, as a result of severe speech dysfunction, may also have a more severe level of $\mathrm{CP}$ which also limits the production of gestures. Furthermore, these results could have implications for language intervention, putting a direct focus on strengthening both receptive language and gesture skills, especially for children who are nonspeaking.

The children who are speaking performed above the 16 month age equivalency level for all measures on the MacArthur Communicative Development Inventory: Words \& Gestures, except early gestures and total gestures. Although these children had age equivalencies for early and total gestures within the 8 to 16 month range, their age equivalencies were still higher than those of the children who are nonspeaking for the same measures. This may suggest that children who are speaking and are without severe motor speech dysfunction may produce higher numbers of gestures, because gestures and language production have been highly correlated (Owens, 1988). It could also mean that children with 
$\mathrm{CP}$ who are speaking may have less severe levels of $\mathrm{CP}$ and are, thus, able to gesture more than their nonspeaking peers. However, there were two outliers in the group of children who are speaking which drastically decreased this group's number of mean gestures. These two children did not score any points in early, later, and total gestures because their parents did not fill in these sections.

Both groups were extremely delayed in early and total gestures when compared to typically developing children. However, while the nonspeaking group was also delayed in later gestures, the speaking group scored above the $50^{\text {th }}$ percentile at 16 months for later gestures. This is surprising, because, children should show proficiency in early gestures before later gestures. Perhaps for some of the early gestures parents typically had their child positioned on their lap and dyadic interaction was decreased because caregivers were inclined to be more physically controlling of their children, as Redditi-Hanzlik and Stevenson (1986) found. Since the difference between gesture production for the two groups was statistically significant for early, later, and total gestures, future research should be conducted which explores the relationships of receptive word acquisition and gesture acquisition versus severity level of $\mathrm{CP}$.

Both groups of subjects were responding to language via physical movements (e.g., turning the head, looking up, or stopping what they were doing). This is a positive sign that these children are equating language in their environment with change, specific people, places or things, or with themselves. Although, and not surprisingly, the children who are speaking had much higher rates of imitating and labeling with words, it would be interesting to compare rates of imitation between the two groups for imitation of physical gestures. Although, the children who are speaking had higher scores for gesture production than the 
children who are nonspeaking, both groups were still very delayed. Furthermore, as assessed on Part II-F, parents reported that $100 \%$ of the children who are speaking demonstrated behaviors that are truly symbolic, while the children who are nonspeaking did not demonstrate any truly symbolic behaviors. This may indicate a lag in cognitive functioning for the children who are nonspeaking and a possible inability to investigate or request imaginary play with peers.

\section{Limitations of the Study}

Some parents wrote notes or talked with this researcher about possible modifications of the MacArthur Communicative Development Inventory: Words \& Gestures, as well as some misunderstandings they had when filling out the questionnaire. The information that the parents shared would make this researcher inclined to change some of the procedures of this study in future research and brought to light some modifications of the questionnaire that would be more appropriate for children with CP. First, parents should fill out the questionnaire in the presence of the researcher. This should alleviate misunderstandings of directions and ensure that the questionnaire is completed correctly. Second, the researcher would be able to assess whether or not the parents' definition of an expressive word (word approximation, one sound, consistent use of a jargon word) or the parents' criteria for how they assess their child's comprehension of words and phrases is the same as the researcher's parameters.

By creating a questionnaire that caters to children with physical disabilities, the data are going to be more specific and representative of their strengths and weaknesses. For example, the gesture production response categories of the MacArthur Communicative Development Inventory: Words \& Gestures, as opposed to being a yes/no format, could be 
modified to delineate the following: the child makes the gesture by themselves, the child makes the gesture with minimal assistance from the caregiver, the child requests that a parent manipulate the child's hands for a gesture, or the child does not make this gesture.

Furthermore, the socioeconomic status of the children, as well as the severity of $\mathrm{CP}$ was not determined in this study. These two factors should be considered in future research, and may have been a factor in the performance of some of the subjects.

\section{Research}

Future research in the area of language and gesture development of children with $\mathrm{CP}$ is necessary for many reasons. First, studies should be conducted with larger numbers of subjects so that a more representative body of descriptive data could be obtained.

Comparing children with $\mathrm{CP}$ who are speaking and nonspeaking to children with typical development is not really giving a true picture of where the children with $\mathrm{CP}$ should be developmentally. Gathering more descriptive data based on a large sample would give clinicians the opportunity to measure the achievement of a child who has CP to his/her peers.

Second, studies should be conducted using the MacArthur Communicative Development Inventory: Words \& Gestures in conjunction with other standardized language and cognitive measures. An analysis could be conducted to see if there is a correlation between cognitive status, language proficiency, and performance on a parent questionnaire. This may allow researchers to make inferences about the cognitive skills of the subjects by using the MacArthur Communicative Development Inventory: Words \& Gestures scores, since many communication and cognitive milestones are so closely tied together. 
Third, it is imperative that future research be conducted which assesses the practical use and valid measure of the MacArthur Communicative Development Inventory: Words \& Gestures for use with populations that have not had typical development. This would allow researchers to see whether or not a new questionnaire specifically designed for and normed on children with disabilities should be constructed.

Fourth, future research should be conducted to develop a parent questionnaire which specifically assesses the language and gesture development of children with physical disabilities. This type of questionnaire would allow researchers to probe subtle performance in the areas of language and gestures. For example, the gesture production section of a questionnaire could include response categories tailored to a child with physical impairments (e.g., Does your child produce this gesture with minimal assistance?)

Fifth, research which looks at the different semantic categories that are understood and used by children with CP should be explored. The MacArthur Communicative Development Inventory: Words \& Gestures has 19 different word categories for the vocabulary section. This research may provide some insight as to the child's individual strengths and weaknesses in comprehension and production of common words and phrases in different categories. This could be useful information to have when considering word and symbol selection if a child was using an AAC system.

In addition, it would also be interesting to use the MacArthur Communicative Development Inventory: Words \& Gestures before and after speech and language intervention programs or implementation of an AAC system. This research could help clinicians assess a child's growth in the areas of language and gesture development post- 
treatment, as well as directing clinicians toward possible language and gesture target areas for early intervention programs. 


\section{REFERENCES}

Acredolo, L., \& Goodwyn, S. (1988). Symbolic gesturing in normal infants. Child Development, 59, 450-466.

Adler, S. (1975). The non-verbal child: An introduction to pediatric language pathology. Springfield, IL: Charles C. Thomas Publisher.

Bates, E., Benigni, L., Bretherton, I., Camaioni, L., \& Volterra, V. (1979). The emergence of symbols: Cognition and communication in infancy. New York: Academic Press.

Bates, E., Camaioni, L., \& Volterra, V. (1975). The acquisition of perfomatives prior to speech. Merril-Palmer Quarterly, 21, 205-216.

Bayley, N. (1969). Bayley Scales of Infant Development. New York: The Psychological Corporation.

Benedict, H. (1979). Early lexical development: Comprehension and production. Child Language, 6, 183-200.

Beringer, V., \& Gans, B. (1986). Language profiles in nonspeaking individuals of normal intelligence with severe cerebral palsy. Augmentative and Alternative Communication, 11, 45-50.

Clayton, T. (1989). Taber's cyclopedic medical dictionary. Philadelphia: F.A. Davis Company.

Coplan, J., \& Gleason, J. (1988). Unclear speech: Recognition and significance of unintelligible speech in preschool children. Pediatrics, 82, 447-452.

Creaghead, N., Newman, P., \& Secord, W. (1989). Assessment and remediation of articulatory and phonological disorders ( ${ }^{\text {nd }}$ ed.). Columbus, $\mathrm{OH}$ : Merrill Publishing Company.

Dale, P. (1991). The validity of a parent report measure of vocabulary and syntax at 24 months. Journal of Speech and Hearing Research, 34, 565-571.

Dale, P., Bates, E., Reznick, J., \& Morisset, C. (1989). The validity of a parent report instrument of child language at twenty months. Journal of Child Language, 16, 239249. 
Fein, G. (1981). Pretend play in childhood: An integrative view. Child Development, 52, 1095-1118.

Fenson, L., Dale, P., Reznick, J., Thal, D., Bates, E., Hartung, J., Pethick, S., \& Reilly, J. (1993). MacArthur communicative development inventories: User's guide and technical manual. San Diego: Singular Publishing Group, Inc.

Fenson, L., Kagan, J., Kearsley, R., \& Zelazo, P. (1976). The developmental progression of manipulative play in the first two years. Child Development, 47, 232-236.

Fenson, L., \& Ramsay, D. (1981). Effects of modeling action sequences on the play of twelve-, fifteen-, and nineteen-month-old children. Child Development, 32, 1028-1036.

Fletcher, P., \& Garman, M. (1986). Language acquisition. New York: Cambridge University Press.

Gardener, M. F. (1979). The expressive one-word picture vocabulary test. Novato, CA: Academy Therapy Publishing Company.

Goldfield, B., \& Reznick, J. (1990). Early lexical acquisition: rate, content, and the vocabulary spurt. Journal of Child Language, 17, 171-183.

Hardy, J. (1983). Cerebral Palsy. Englewood Cliffs, NJ: Prentice Hall.

Haynes, W., \& Shulman, B. (1994). Communication development: Foundations, processes, and clinical applications. Englewood Cliffs, NJ: Prentice Hall.

Johnson-Martin, N., Wolters, P., \& Stowers, S. (1987). Psychological assessment of the nonvocal, physically handicapped child. Augmentative and Alternative Communication, 11, 23-38.

Light, J., Binger, C., \& Kelford-Smith, A. (1994). Story reading interactions between preschoolers who use AAC and their mothers. Augmentative and Alternative Communication, 10, 255-268.

Love, R. (1992). Childhood motor speech disability. New York: MacMillan Publishing Company.

Lloyd, L., \& Karlan, G. (1983). Non-speech communication symbols and systems: Where have we been and where are we going? Augmentative and Alternative Communication, 28, 3-20.

Mysak, E. (1980). Neurospeech therapy for the Cerebral Palsied: A neuroevolutional approach. New York: Teachers College Press. 
Nicolosi, L., Harryman, E., \& Kresheck, J. (1996). Terminology of communication disorders: Speech, language, hearing ( $4^{\text {th }}$ ed.). Maryland: Williams and Wilkins.

O'Brien, L., \& Andresen, J. (1983). A family matter: Stimulating communication in the young cerebral palsied child. Teaching Exceptional Children, 16, 47-50.

Owens, R. (1988). Language development: An introduction. Columbus, $\mathrm{OH}$ : Merrill Publishing Company.

Pannbacker, M., \& Middleton, G. (1994). Introduction to clinical research in communication disorders. San Diego: Singular Publishing Group, Inc.

Piaget, J. (1962). Play, dreams, and imitation in childhood. New York: W. W. Norton \& Company.

Redditi-Hanzlik, J. (1990). Nonverbal interaction patterns of mothers and their infants with cerebral palsy. Education and Training in Mental Retardation, 90, 333-343.

Redditi-Hanzlik, J., \& Stevenson, M. (1986). Interaction of mothers with their infants who are mentally retarded, retarded with cerebral palsy, or nonretarded. American Journal of Mental Deficiency, 5, 513-520.

Rescorla, L. (1980). Category development in early language. Journal of Child Language, 8, 225-238.

Rescorla, L. (1991). Identifying expressive language delay at age two. Topics in Language Disorders, 11, 14-20.

Sander, E. (1972). When are speech sounds learned? Journal of Speech and Hearing Disorders, 37, 55-63.

Stoel-Gammon, C. (1987). The phonological skills of two year olds. Language, Speech, and Hearing Services in Schools, 18, 323-329.

Stoel-Gammon, C. (1991). Normal and disordered phonology in two-year-olds. Topics in Language Disorders, 11, 21-32.

Teal, W., \& Sulzby, E. (1986). Emergent literacy: Writing and reading. Norwood, NJ: Ablex.

Terrel, B., \& Schwartz, R., (1988). Object transformations in the play of young children. Journal of Speech and Hearing Disorders, 53, 459-466.

Thal, D., \& Bates, E. (1988). Language and gesture in late talkers. Journal of Speech and Hearing Research, 31, 115-123. 
Thal, D., \& Tobias, S. (1994). Relationships between language and gesture in normally developing and late-talking toddlers. Journal of Speech and Hearing Research, 37, 157-170.

Wehrabian, A. (1970). Measures of vocabulary and grammatical skills for children up to age six. Developmental Psychology, 2, 439-446.

Wetherby, A., Cain, D., Yonclas, D., \& Walker, V. (1988). Analysis of intentional communication of normal children from the prelinguistic to the multiword stage. Journal of Speech and Hearing Research, 31, 240-252. 
APPENDIX A

INFORMED CONSENT FORM AND COVER LETTER

FOR SUBJECTS 
INFORMED CONSENT FORM

I, , agree to take part in this research project on the verbal and gestural behaviors of children with cerebral palsy, under the direction of Dr. Rhea Paul.

I understand that the study involves talking on the telephone with Ann Friel, and fill out a questionnaire (the MacArthur Communicative Development Inventory: Words \& Gestures), which asks questions about the verbal and gestural behaviors of my child, and may take from 20 to 40 minutes to fill out.

I understand that as a result of this study the information gathered on the questionnaire will be analyzed and presented in a thesis at the Speech and Hearing Sciences Department at Portland State University.

Dr. Rhea Paul and Ann Friel have told me that the purpose of the study is to learn about the language and gestures used by or understood by children between the ages of 2 and 5 years that have cerebral palsy. I understand that the information gathered in this study may be used for future research of this nature by other graduate students at the Speech and Hearing Sciences Department at PSU.

I may not receive any direct benefit from taking part in this study, but the information that I give may help to increase knowledge in this field and may help others in the future. Ann Friel has offered to answer any questions I have about the study and what I am expected to do. She has promised that all information I give will be kept confidential to the extent permitted by law, and that the names of all people in the sudy will be kept confidential.

I understand that I do not have to take part in this study and that this will not hurt my relationship with Portland State University or the agency from which I received the information about the study. I have read and understand the above information and agree to take part in this study.

TELEPHONE NUMBER

Ann Friel (home) . . . . . . . . . . . . . . . . . . (503) 234-4137

Dr. Rhea Paul, Portland State University . . . . . . . . (503) 725-3142

Human Subjects Committee, Portland State University . . (503) 725-3417 
Dear Parents:

I am a graduate student at Portiand State University in the Department of Speech and Hearing Sciences. As a requirement of the Masters program, I will be conducting a research project which will assess the communicative development of children who have cerebral palsy between the ages of 2 and 5 years old. I will be using a parent questionnaire, the MacArthur Communicative Development Inventory: Words \& Gestures, to obtain information for my study. I will be supervised by Rhea Paul, $\mathrm{Ph} . \mathrm{D}$., a graduate professor in the Deparment of Speech and Hearing Sciences at Portiand State University.

To participate in the study, you will need to read and fill out the attached consent form and send it to me in the envelope provided. Feel free to call myself or Dr. Rhea Paul if you have any questions about the study. Once I have received the consent form and spoken with you on the telephone about the study, a packet will be sent to your home. The packet will contain the following: (a) directions for filling out the MacArthur Communicative Development Inventory: Words \& Gestures, (b) the MacArthur Communicative Development Inventory: Words \& Gestures, and (c) a previously stamped and addressed envelope in which to renum the questionnaire.

I am conducting this research in order to gather more information on the verbal and gestural patterns of children with cerebral palsy. The information obtained from the questionnaire will be analyzed and presented in my thesis the following year and may be used in future research studies conducted at Portland State University which are of this same nature. All questionnaires will be kept confidential and only the information on type of cerebral palsy represented and communicative patterns in the study will be presented in the paper.

Dr. Rhea Paul and I would greatly appreciate your interaction in this study, and can be contacted at the following numbers to answer any questions you might have about the study: Ann Friel (503) 234-4137, Dr. Rhea Paul (503) 725-3142.

Sincerely, 


\section{APPENDIX B}

DIRECTIONS FOR FILLING OUT THE MacARTHUR COMMUNICATIVE DEVELOPMENT INVENTORY: WORDS \& GESTURES 
Dear Parent(s):

I would like to take a moment and thank you again for participaring in this study. In this envelope, I have enclosed a questionnaire, the MacArthur Communicative Development Inventory: Words \& Gestures, a copy of your Informed Consent Form, and a self-addressed and stamped envelope. This letter will belp you complete the questionnaire and return it to me.

1. Please fill out the information at the top of the questionnaire.

2. For Par I Early Words, please read the directions at the top of each lettered block, A-D (1-19). Fill in the correct circle with a No. 2 pencil. Part I Early Words contains questions about words your child understands and may use in their vocabulary. Please fill in what information pertains to your child and leave the other items blank.

3. For Part II Actions and Gestures, please read the directions at the top of the lettered blocks A-F. Again, please fill in what pertains to your child and leave the other items blank.

4. On the last page in the Other Comments block, please put the following information if you know the answer or which to share the information. If you do not know the answer to a question, you may leave it blank. This information will allow us to take into consideration other factors that may be influencing your child's communication skills. This information will also allow us to see how varied our sample population is with regard to socioeconomic level and race.

a. What type(s) of cerebral paisy do(es) your child bave?

b. Does your child have any accompanying syndromes, disabilities, or bandicaps?

c. If koow, at what cognitive or mental age level is your child functioning?

d. Is your child using an augmentative communication system? If so, what type/name?

e. Does your child have normal hearing or a hearing loss?

f. What is your total annual household income from all sources?

g. What race do you consider your child to be?

h. Has your child received speech and language intervention? If so, for how long?

5. Put the questionnaire in the addressed and stamped envelope and mail off?

Also, if there are any comments, questions, or if you would like to share more information about your child's communication skills, feel free to write on a sheet of paper and attach it to the questionnaire.

Please feel free to call me or leave a message on my machine if you have any questions about the questionnaire or concerns about the study.

Sincerely,

Ann Friel - (503) 508-8768 


\section{APPENDIX C}

THE MACARTHUR COMMUNICATIVE DEVELOPMENT INVENTORY: WORDS \& GESTURES 


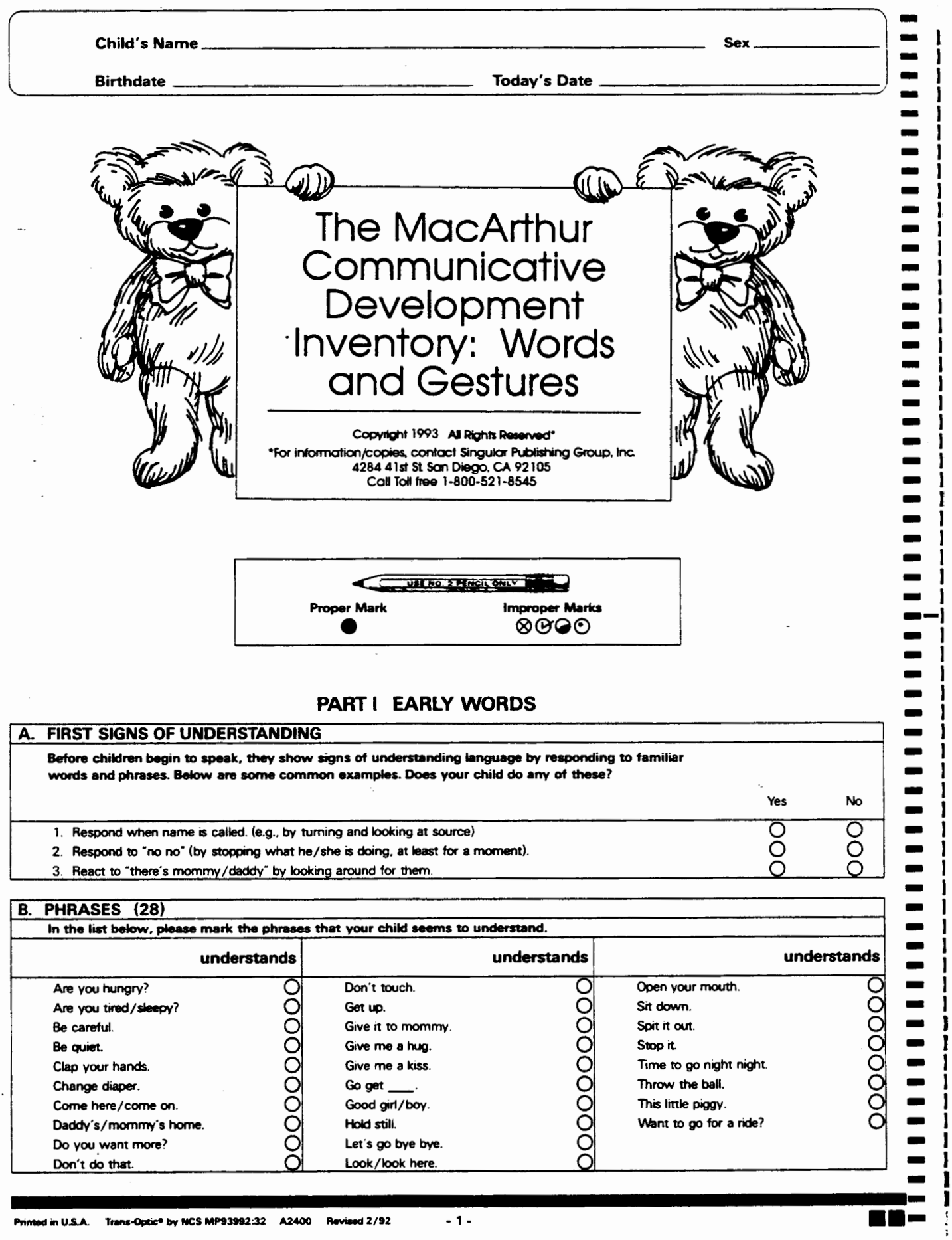




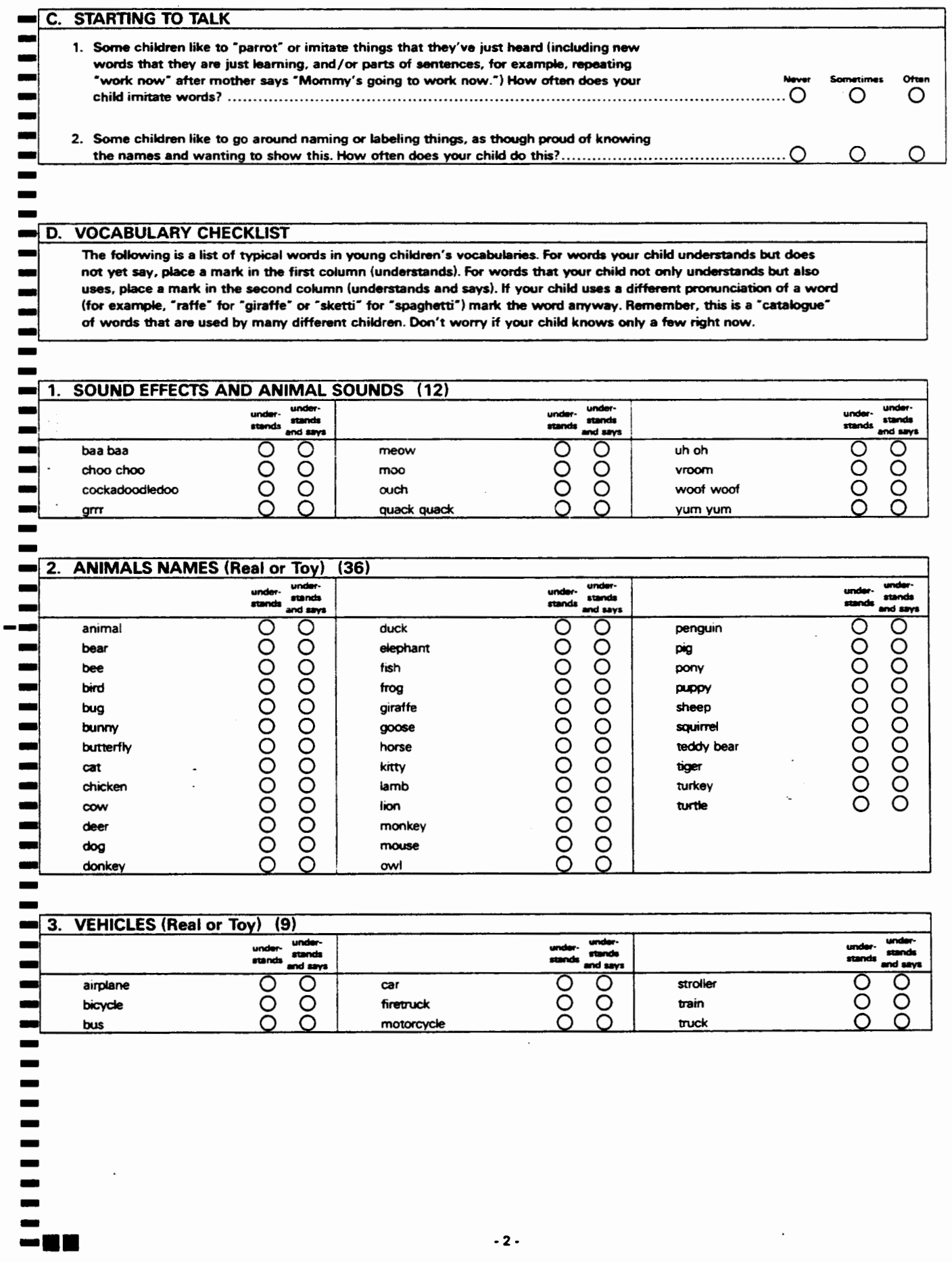




\begin{tabular}{|c|c|c|c|c|c|}
\hline \multicolumn{6}{|c|}{ 4. TOYS $(8)$} \\
\hline & $\begin{array}{l}\text { under- undor- } \\
\text { stands stonds } \\
\text { and seavs }\end{array}$ & & $\begin{array}{l}\text { under- cunder- } \\
\text { stands stonds } \\
\text { and gavis }\end{array}$ & & 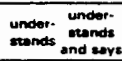 \\
\hline ball & 0 & book & 7 & pen & 00 \\
\hline balloon & $\Omega$ & bubbles & & tor & 0 \\
\hline block & 0 & doll & 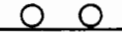 & & \\
\hline
\end{tabular}

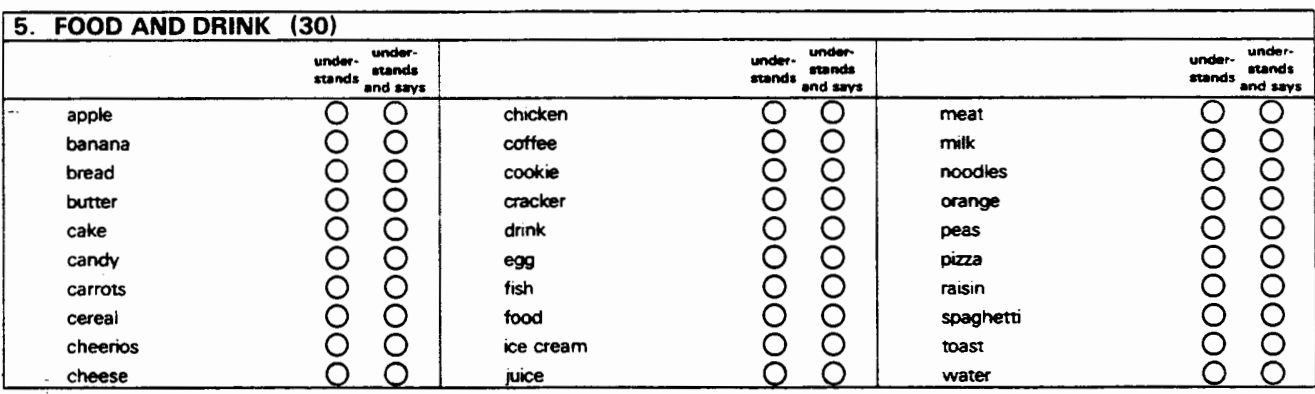

\begin{tabular}{|c|c|c|c|c|c|}
\hline \multicolumn{6}{|c|}{ 6: CLOTHING (19) } \\
\hline . & $\begin{array}{l}\text { under. under. } \\
\text { menends stands } \\
\text { and eave }\end{array}$ & & $\begin{array}{l}\text { under- undor- } \\
\text { stonds and sors }\end{array}$ & & $\begin{array}{l}\text { undor. under- } \\
\text { standese stonds }\end{array}$ \\
\hline beads & & hat & 00 & shoe & 0 \\
\hline bib & & jacket & & shorts & \\
\hline boots & & jeans & & sock & \\
\hline button & & necklace & & sweater & J \\
\hline coat & & pajamas & & zipper & \\
\hline diaper & O & pants & & & \\
\hline dress & 0 & shirt & & & \\
\hline
\end{tabular}

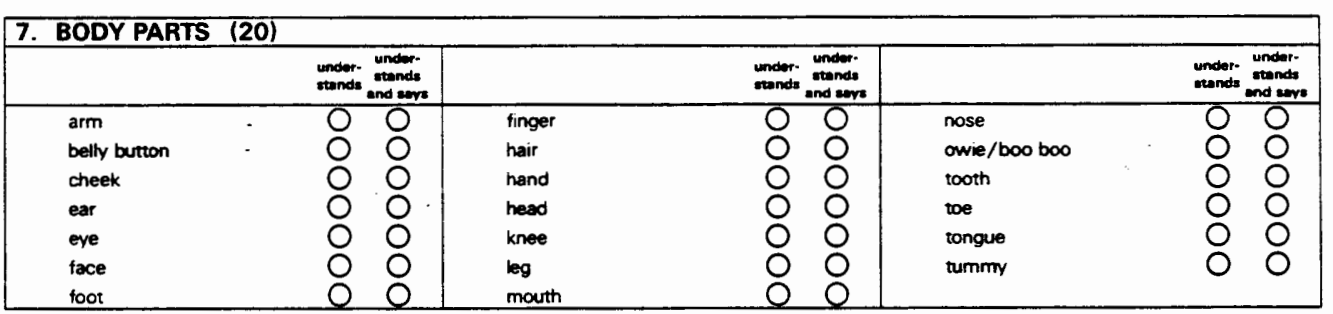

\begin{tabular}{|c|c|c|c|c|c|}
\hline \multicolumn{6}{|c|}{ 8. FURNITURE AND ROOMS (24) } \\
\hline & $\begin{array}{l}\text { under. under. } \\
\text { stanth } \\
\text { and ends }\end{array}$ & & 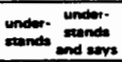 & & $\begin{array}{l}\text { under. undor. } \\
\text { sunds stonde }\end{array}$ \\
\hline bathroom & & drawer & & refngerator & \\
\hline bathtub & & garage & & rocking chair & \\
\hline bed & & high chair & & $\sin k$ & \\
\hline bedroom & & kitchen & ) & stairs & \\
\hline chair & & living room & & stove & \\
\hline couch & & oven & & table & \\
\hline crib & & play pen & 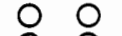 & TV & O \\
\hline door & 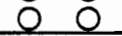 & potty & & window & 0 \\
\hline
\end{tabular}




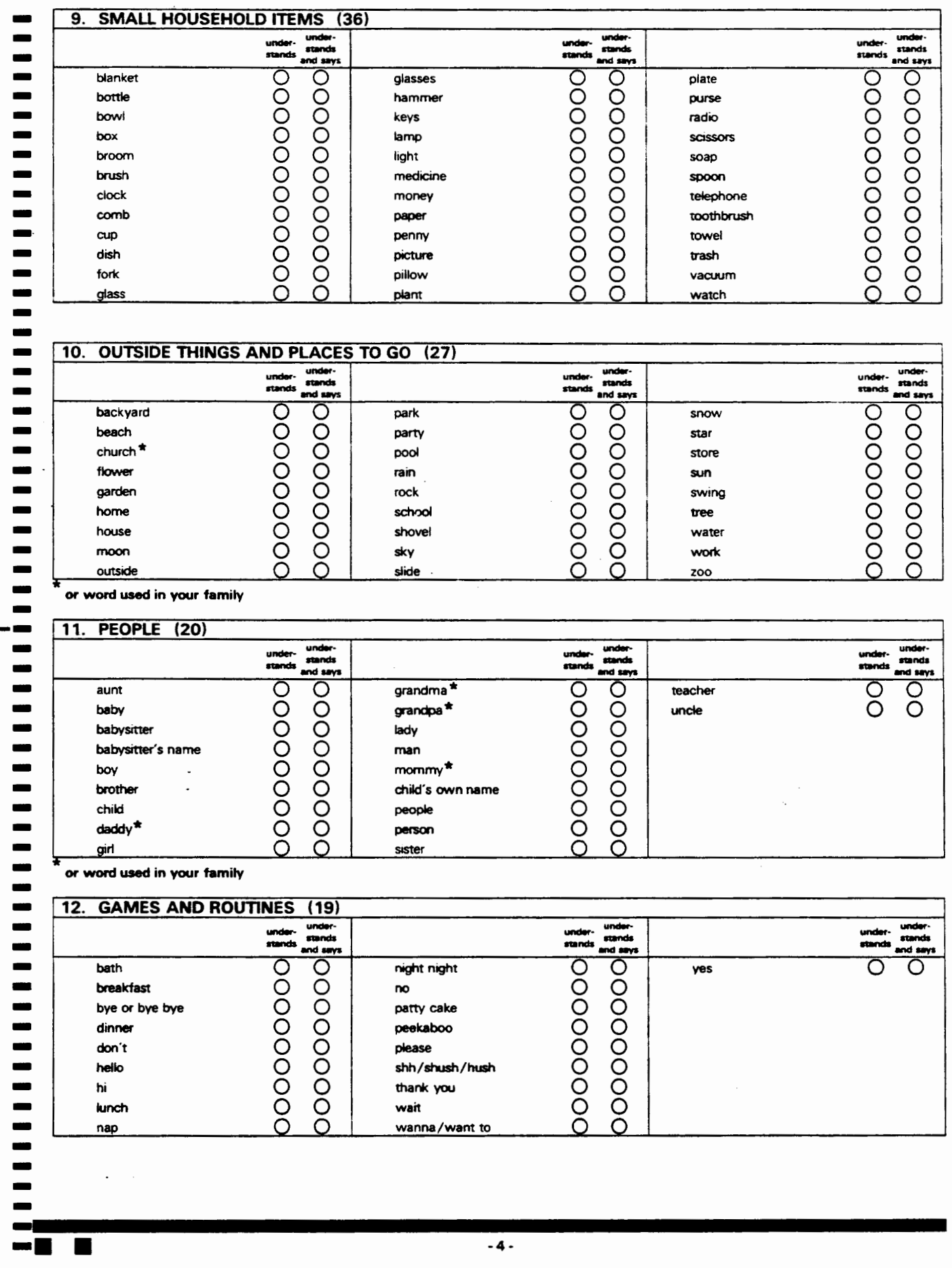




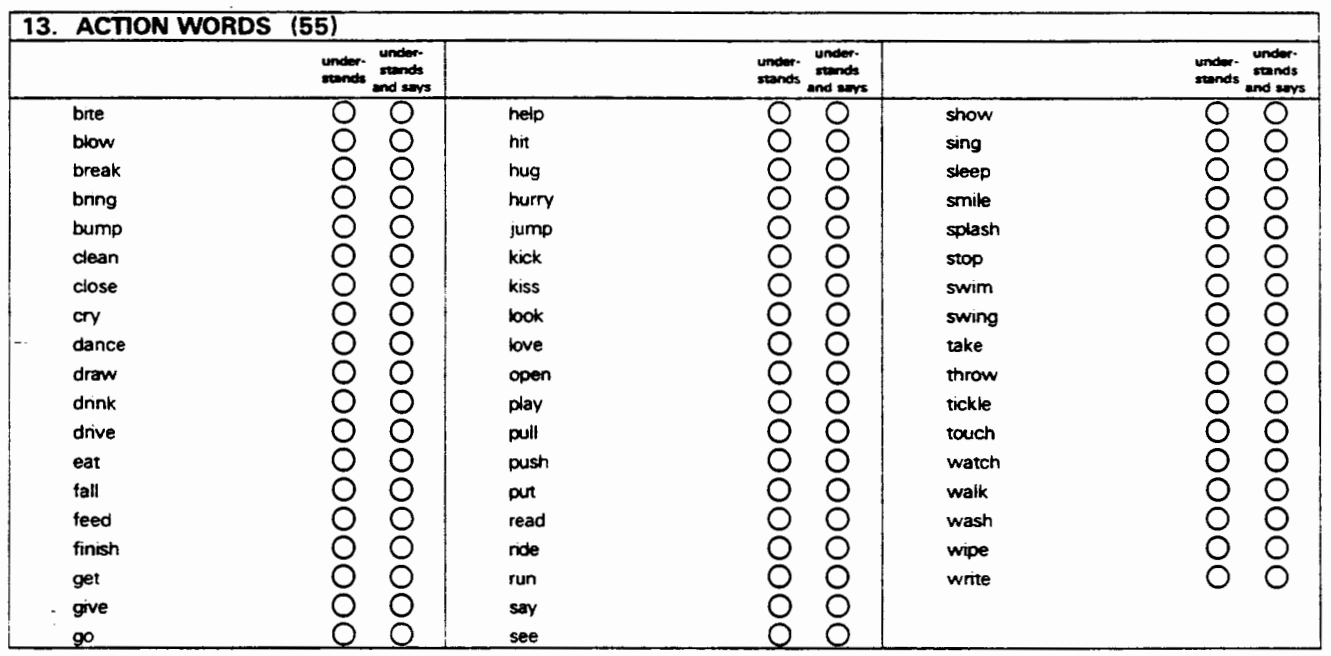

14. WORDS ABOUT TIME (8)

\begin{tabular}{|c|c|c|c|c|c|}
\hline & $\begin{array}{l}\text { under. under. } \\
\text { stends stonds } \\
\end{array}$ & & $\begin{array}{l}\text { under. under- } \\
\text { stands stands } \\
\text { and sons }\end{array}$ & & $\begin{array}{l}\text { under. under- } \\
\text { strends sands } \\
\text { and severs }\end{array}$ \\
\hline day & 0 & nught & 0 & tomorrow & $\bar{O}$ \\
\hline tater & & now & & tonight & J \\
\hline morning & 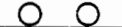 & today & & & \\
\hline
\end{tabular}

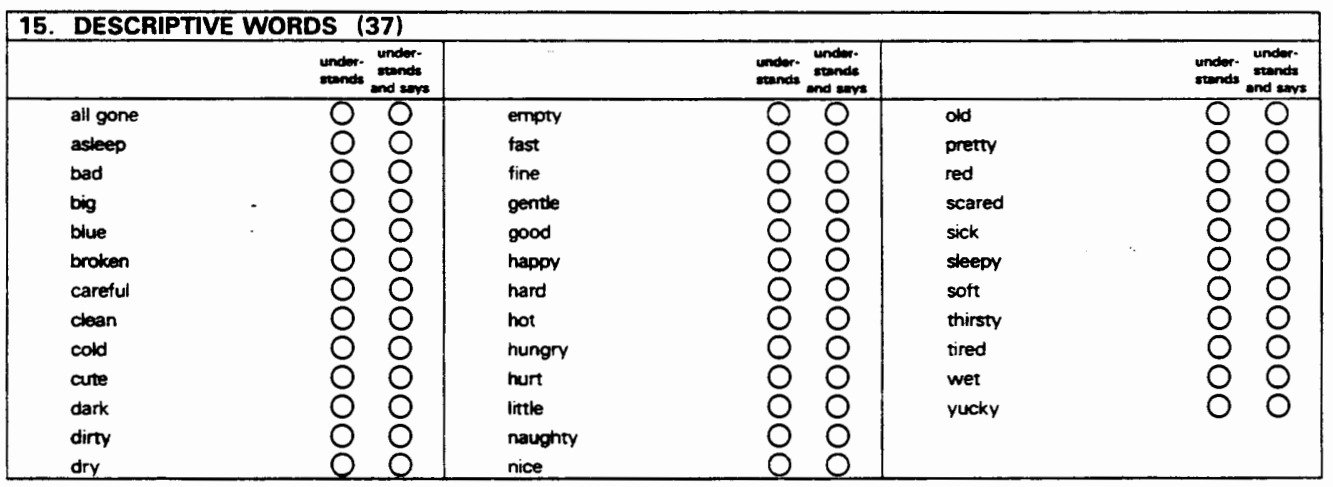

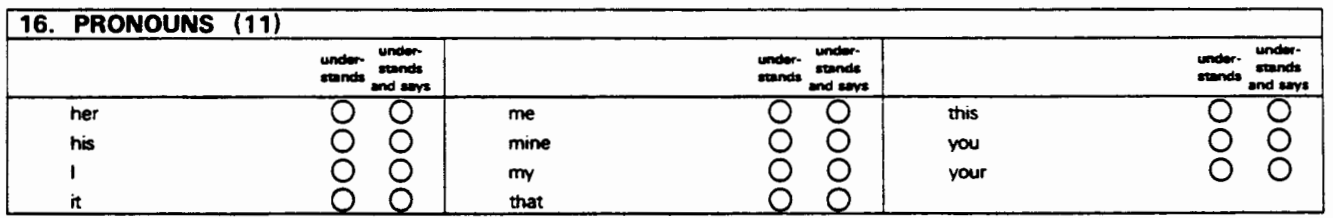




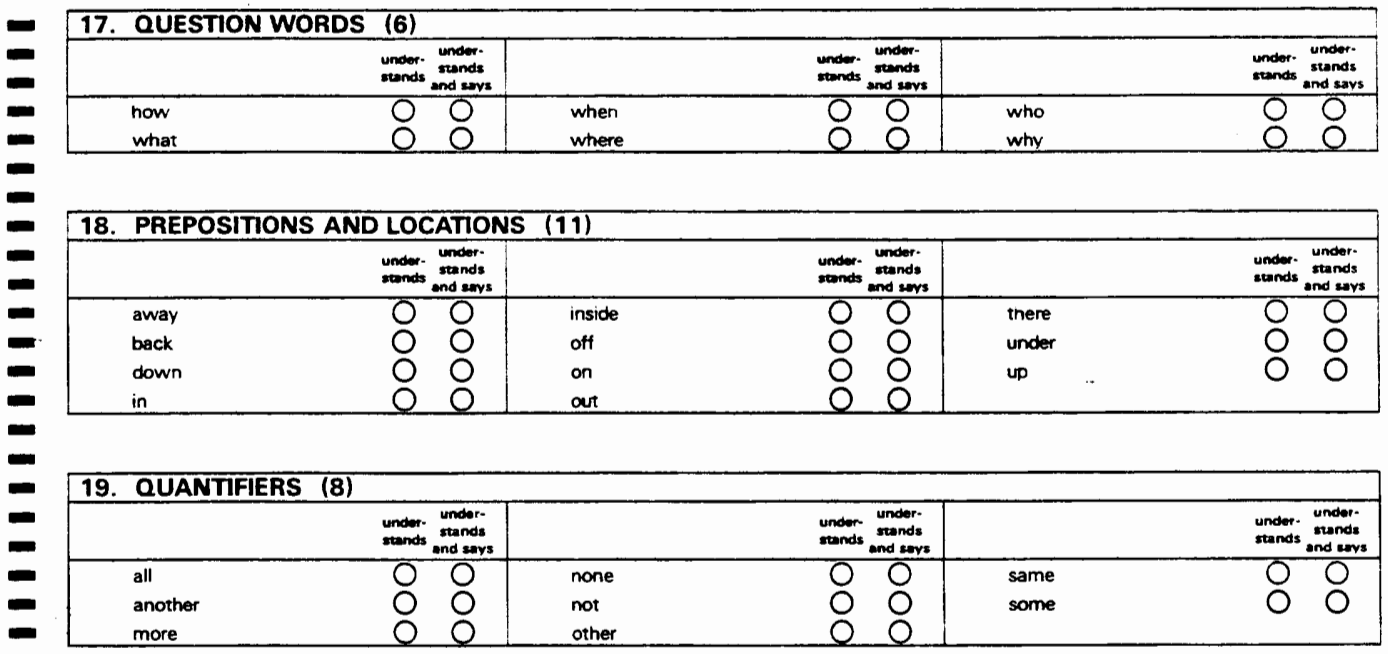

\section{PART II ACTIONS AND GESTURES}

\section{A. FIRST COMMUNICATIVE GESTUURES}

When infants are first learning to communicate, they often use gestures to make their wishes known. For each item below, mark the line that describes your child's actions right now.
1. Extends arm to show you something he/she is holding
2. Reaches out and gives you a toy or some object that he/she is holding.
3. Points (with arm and index finger extended) at some interesting object or event
4. Waves bye-bye on his/her own when someone leaves.
5. Extends his/her arm upward to signal a wish to be picked up.
6. Shakes head "no".
7. Nods head "yes".
8. Gestures "hush" by placing finger to lips.
9. Requests something by extending arm and opening and closing hand.
10. Blows kisses from a distance.
11. Smacks lips in a "yum yum" gesture to indicate that something taste good

12. Shrugs to indicate "all gone" or "where'd in go"

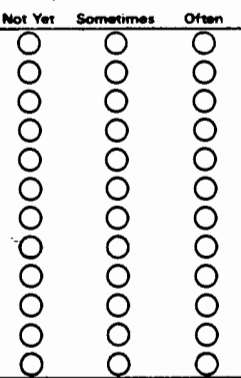

\section{B. GAMES AND ROUTINES}

Does your child do amy of the following?
1. Play peekaboo
2. Play patty cake.
3. Play "so big"
4. Play chasing games.
5. Sing.
6. Dance. 


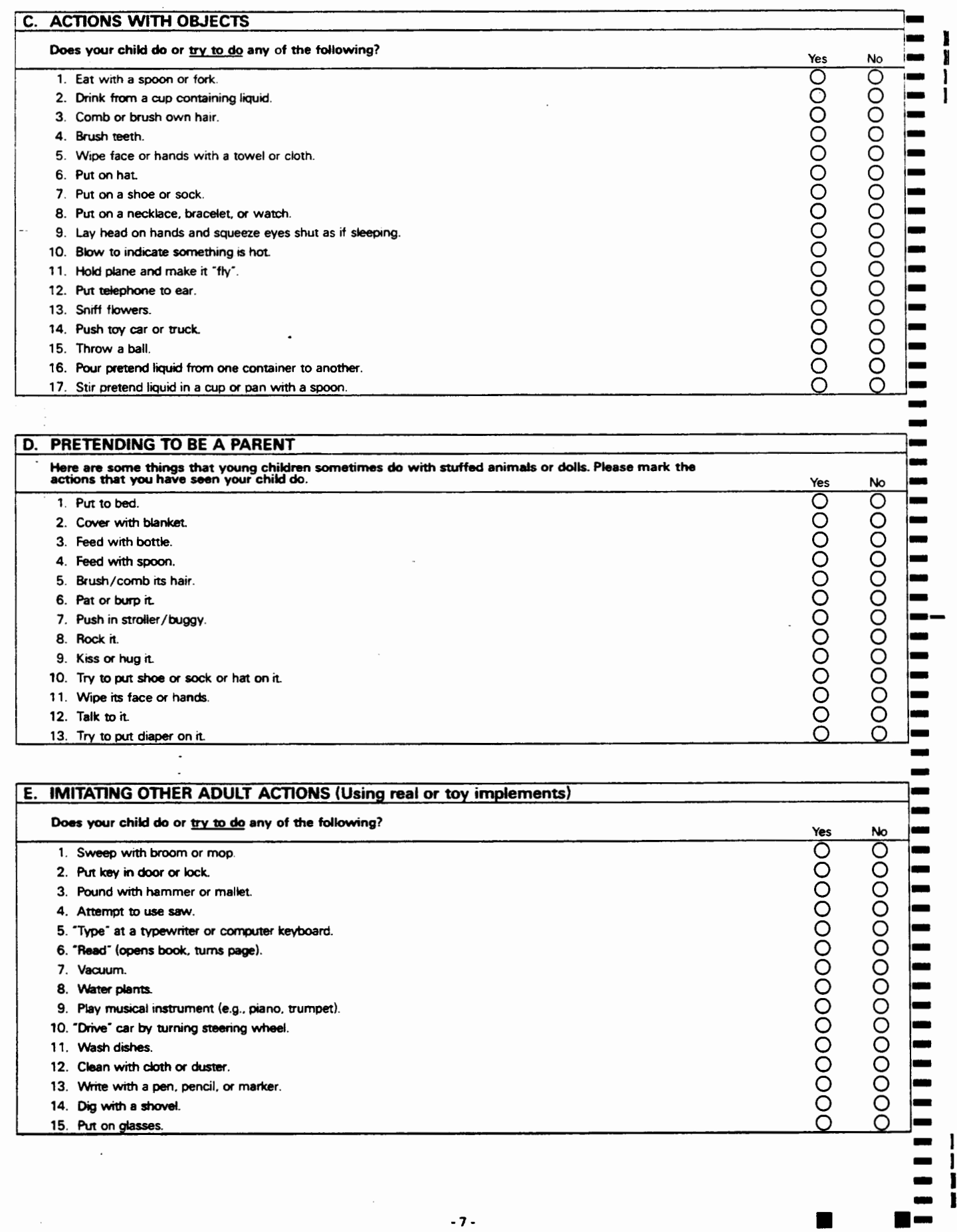




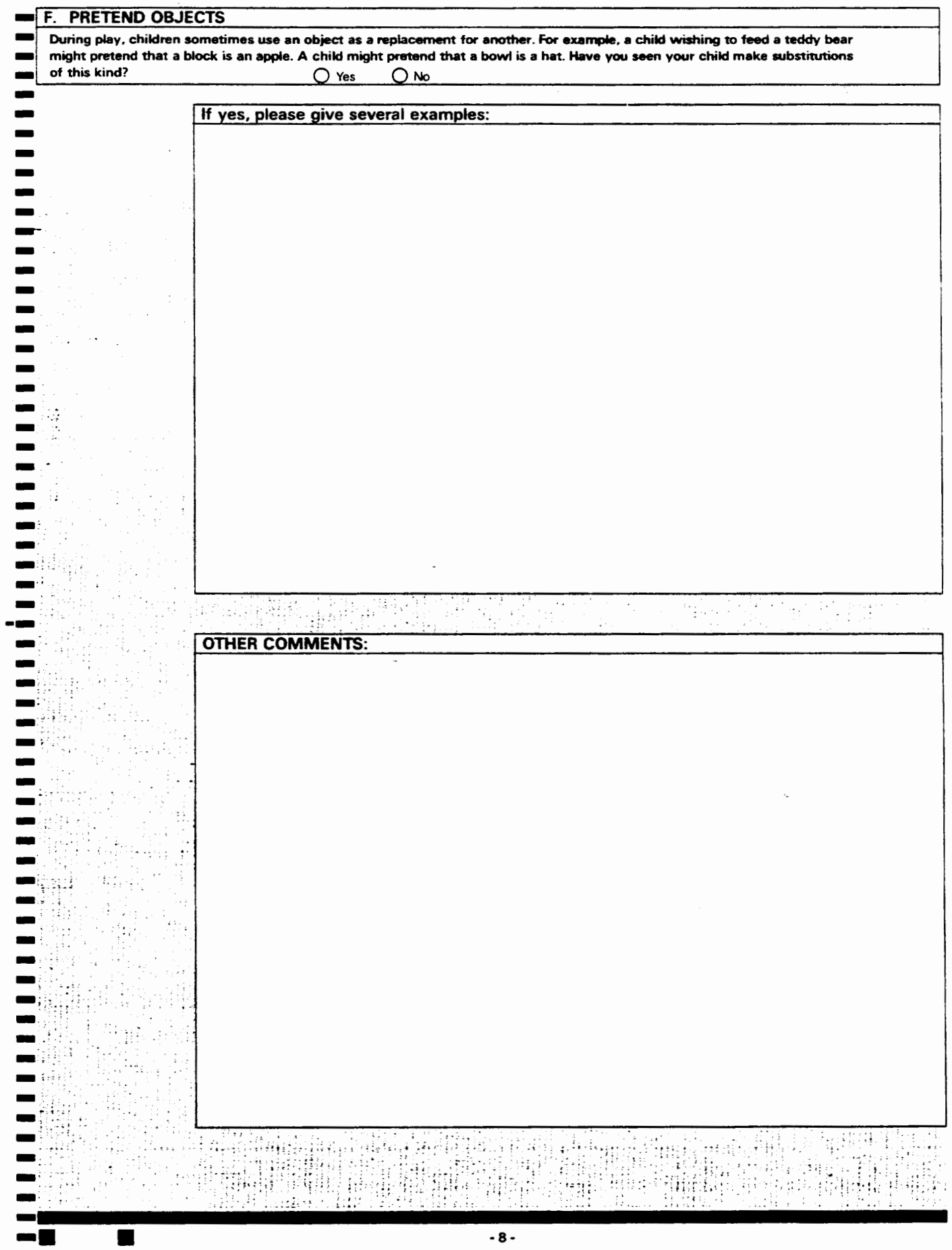




\section{APPENDIX D}

THE MACARTHUR COMMUNICATIVE DEVELOPMENT INVENTORY: WORDS AND GESTURES

CHILD REPORT FORM 
Administration, Scoring, and Interpretation

\section{MacArthur CDI/Words and Gestures \\ Child Report Form}

Child's Name

Sex M F

Date of birth

Test date

Name of person

completing form

Age (in months)

Relation to child

\section{Part I: Early Words}

A First Signs of Understanding

1. Responds when name is called: Yes No

2. Responds to "no no": $\quad$ Yes No

3. Reacts to "there's mommy/daddy": Yes

B. Phrases Understood: Number

-

Fercent of "yes" answers for each

quesion exceseds $84 \%$ at 8 months

and $90 \%$ from 9 months on.

C. Starting to Talk

1. Imitation:

2. Labeling:

Percentile score

(See lable A-1 or A-2)

Percent of "yes" answees at this child's age. (See Figure 2-1)

Yes No

Yes No

D. Vocabulary Checklist

1. Words understood:

Number

Percentile score

2. Words produced

Number

Percentile score

See libble $A-3$ or $A-4)$

(sec bable $A-5$ or $A-6)$

Part II: Actions and Gestures
A-B. Early Gestures:
C-E. Later Gestures:
A-E. Total Gestures:

Number

Percentile score

Number

Percentile score

Number

(See bable A-11 or. A-12)

Percentile score

(See iable $A-7$ or $A-8$ )

\section{Summary}

Section

Percentile Score

Section

Percentile Score

Phrases understood:

Vocabulary comprehension:

Earty gestures:

Vocabulary production:

Later gest:ires:

Total gestures: 